\title{
The Prosodic Expression of Sarcasm vs. Sincerity by Heritage Speakers of Spanish
}

\author{
Rajiv Rao ${ }^{1, *(\mathbb{D})}$, Ting $\mathrm{Ye}^{2}$ and Brianna Butera ${ }^{3}$ \\ 1 Department of Spanish \& Portuguese, University of Wisconsin-Madison, Madison, WI 53706, USA \\ 2 Department of Biostatistics, University of Washington, Seattle, WA 98195, USA; tingye1@uw.edu \\ 3 Department of World Languages and Literatures, University of Memphis, \\ Memphis, TN 38152, USA; bjbutera@memphis.edu \\ * Correspondence: rgrao@wisc.edu
}

check for updates

Citation: Rao, Rajiv, Ting Ye, and Brianna Butera. 2022. The Prosodic Expression of Sarcasm vs. Sincerity by Heritage Speakers of Spanish. Languages 7: 17. https://doi.org/ 10.3390/languages7010017

Academic Editors: Christine Shea and Ji Young Kim

Received: 20 October 2021

Accepted: 18 January 2022

Published: 21 January 2022

Publisher's Note: MDPI stays neutral with regard to jurisdictional claims in published maps and institutional affiliations.

Copyright: (C) 2022 by the authors. Licensee MDPI, Basel, Switzerland. This article is an open access article distributed under the terms and conditions of the Creative Commons Attribution (CC BY) license (https:// creativecommons.org/licenses/by/ $4.0 /)$.

\begin{abstract}
Motivated by existing research gaps exploring heritage Spanish, the current study analyzes the prosodic manifestation of sarcasm versus sincerity in 19 English-dominant, English-Spanish bilinguals residing in the Midwest region of the USA. In order to explore cross-generational effects and source input varieties, a subset of participants from within the same family was analyzed, including their Spanish-dominant, adult immigrant parents, but only for Spanish. Participants produced sarcastic and sincere utterances in response to contextualized stimuli in both English and Spanish. Data were analyzed for $\mathrm{f0}$ mean, f0 range, and speech rate using Praat. A linear mixedeffects analysis examined the main and interactive effects of language, language dominance, gender, bilingual type, place of birth, and age on sarcasm and sincerity. Results show that sincere speech is faster than sarcastic speech and that speakers have a higher speech rate when speaking English as compared to Spanish. Results show that sincere speech is faster than sarcastic speech and that speakers have a higher speech rate when speaking English compared to Spanish. Results also indicate that the effect of attitude on speech rate can be modified by age, and that the effect of language on speech rate can be modified by age, gender, and dominance, as well as a two-way interactive effect of attitude and language on speech rate. Speaking in Spanish yields a higher f0 mean and range. Results also indicate two-way interactive effects of attitude and bilingual type, and language and dominance on f0 mean and range, as well as a three-way interactive effect of attitude, language, and age on f0 mean. In terms of intrafamilial findings, parents and their adult children pattern the same way in Spanish with respect to speech rate and f0, highlighting the role of source input variety. These results expand our knowledge of how different language experiences and sociolinguistic variables influence prosodic outcomes in heritage speakers of Spanish in the USA.
\end{abstract}

Keywords: sarcasm; sincerity; f0; speech rate; heritage Spanish

\section{Introduction}

Previous research on heritage speakers of Spanish (HSS), most of which has been carried out with English-Spanish bilinguals in the United States, has produced fruitful results in the areas of prosody, including intonation, rhythm, and stress (for recent overviews, see Rao 2019; Rao and Amengual 2021), as well as pragmatics, for example, pragmalinguistic issues like discourse markers, directives, and code-switching, and sociopragmatic issues such as (in)formality and sociolinguistic variation (for recent overviews, see Pinto 2018; Shively 2021). However, the interface between prosody and pragmatics in HSS is a relatively recent area of study that has and will continue to fill current research gaps in the area of heritage language (HL) research. One of these new areas of exploration that highlights the prosody-pragmatics interface is how attitudinal factors, such as the communication of sincerity and sarcasm, are manifested in the speech signal of HSS when producing their two languages. Couched in the issues raised regarding this point, as well as previous discussions of pragmatic processing in bilinguals (e.g., Heredia and Cieślicka 2015; Pavlenko 
2006), the current paper explores how identical utterances are prosodically expressed in both Spanish and English by English-dominant bilinguals residing in Chicagoland, in order to determine precisely how different sociolinguistic factors, such as gender, bilingual type, place of birth, and age contribute to the prosodic outcomes in the expression of sarcasm and sincerity.

The remainder of this paper is organized as follows: Section 2 contextualizes and motivates the current study by offering a general background on sarcasm and its prosodic manifestations and acquisition, as well as an overview of previous relevant work on heritage Spanish prosody, pragmatics, and sociolinguistic considerations that may play a role in the expression of attitude; Section 3 presents details on our participants, data collection instruments, and approaches to acoustic and statistical analyses; Section 4 lays out our results in terms of descriptive and inferential statistics; Section 5 discusses the implications of our findings with respect to how they complement and expand upon previous literature; and Section 6 concludes the paper through a summary of its contributions, along with suggestions for further work on related topics.

\section{Literature Review}

\subsection{Background on Sarcasm}

In general, sarcasm is used by speakers to express an attitude that deliberately indicates contempt, ridicule, or dissatisfaction toward another person or idea, but is disguised as an utterance that would otherwise be considered sincere (Gibbs 2000; Haverkate 1984). Haiman (1998) indicates that sarcasm intentionally uses wordplay involving aggression, and is also linked to humor, particularly related to instances of parody. Culpeper (2005) and Leech (1983) consider sarcasm to be a form of mock politeness in which an utterance that would normally be deemed polite or sincere is used to communicate impolite speech and is perceived as offensive. According to Bousfield (2008), this is considered politeness that is off-record. The use of sarcasm to express this attitude is common when compared to other, more blunt forms of criticism that are recognized as being impolite or insulting, in which the speaker is outright criticizing the addressee and being sincere, i.e. "I think your outfit is hideous" or "the lasagna you made tastes terrible" (Cheang and Pell 2008; Dews et al. 1995; Gerrig and Goldvarg 2000).

\subsection{Prosodic Manifestations of Sarcasm}

In speech interaction, people recognize sarcasm through the identification of a "sarcastic tone of voice," manifested prosodically through cues used by the speaker to indicate a negative attitude, otherwise interpreted as truthful and genuine (Cruttenden 1984). This attitudinal intonation points to speaker behavior, including both intentions and perceptions, within a given interaction (Wichmann 2000). When speakers elect to use sarcasm as opposed to sincerity to communicate, they often modify segmental as well as suprasegmental features, in addition to factors such as word- or phrase-level semantic cues, although the types of modifications vary depending on language variety and register (Haiman 1998). Haiman (1998) indicates that these cues for sarcasm may include changes in duration, nasalization, and variations in $\mathrm{f} 0$ rises and falls. When a speaker opts to use sarcasm as opposed to being sincere, prosodic cues can also be accompanied by contextual non-verbal gestures, for example, eye movement and facial expressions (Rockwell 2000a, 2005).

Previous studies across different languages have exhibited the aforementioned cues in the production of sarcastic utterances. For example, in Fonagy's (1971) study, speakers of Hungarian exhibit extreme syllable lengthening and increased f0 range in utterances with sarcasm. As expected, increased syllable duration leads to an overall slower speech rate, a pattern that is also found in other languages (e.g., Adachi (1996) for Japanese; Culpeper (2005) for British English; Cheang and Pell $(2008,2009)$ for Canadian English and Cantonese; Haiman (1998) for English, Greek, Russian, and Tagalog). The increased f0 range found in Fonagy (1971) is also confirmed by Attardo et al. (2003) and Laval and Bert-Erboul (2005). This is further evidenced by Haiman (1998), where English data 
shows high-low f0 movement in echo statements of sarcasm, as well as those sarcastic utterances where duration indicates a more accurate, sincere interpretation. Opposing the studies that highlight an increased f0 range and changes in duration, Winner (1988) finds that the suppression of $\mathrm{fO}$ is a key identifier of contemptuous sarcasm, pointing to the complexity of sarcasm cues across languages and language varieties. ${ }^{1}$ Still other work on sarcasm indicates that speakers use greater fluctuations of $\mathrm{f} 0$ to add sarcastic tones to an otherwise anticipated or uninteresting statement. For example, in Rockwell's (2007) comparison of acoustic and perceptual cues in sarcasm, results show that sarcasm manifests more strongly on the acoustic level; that is, sarcastic utterances exhibit significantly longer duration, increased $\mathrm{f} 0$ movement and range, and fewer pauses than sincere utterances. ${ }^{2}$ Finally, the results reported by Rao (2013) for Mexican Spanish show significant effects of attitude (i.e., sarcasm versus sincerity) on the rate of speech and $\mathrm{f} 0$ mean at the sentence level, as evidenced through slower speech and lowered f0 in sarcastic expressions. ${ }^{3}$ The data also show that the effects of attitude are greater in male speech than in female speech, where attitudinal differences are either not significant or are less marked for f0 range, duration, and intensity. These results characterize sincere, monolingual Spanish as having an increased $\mathrm{f} 0$ and intensity, especially in male speech. Female speech, on the other hand, as suggested by Rao (2013), is not manifested as strongly via prosody; rather, females may express sarcasm using verbal or non-verbal cues other than prosody (Rockwell 2005). We highlight this study by Rao (2013) because it provided us with methodological inspiration (see Section 2.2), as well as a useful point of comparison; that is, his speakers are all adult immigrants from Mexico to the US, while the primary group of participants we analyze represents HSS who grew up in the US. Following those authors such as Rao (2019) and Rao and Amengual (2021), a comparison between these two speaker groups is more valid and useful since both are bilinguals who have some overlap in geographic and lived experiences, as opposed to comparing HSS to native monolinguals who have always lived in a country in which Spanish is the socially and politically dominant language.

As shown here, the prosody of sarcasm shows differences across languages, and as indicated by Cheang and Pell (2009, p. 1394) in their comparison of English and Cantonese, "prosody is instrumental for marking non-literal intentions in speech such as sarcasm in Cantonese as well as in other languages. However, the specific acoustic conventions for communicating sarcasm seem to vary among languages."

\subsection{Acquisition of Sarcasm}

As discussed in the previous sections, speakers differentiate sincere and sarcastic speech by modifying features such as intonation and speech rate. The way in which speakers acquire the ability to perceive and produce the difference between sincerity and sarcasm, however, is variable. Previous studies show that children acquire pragmatic functions such as sarcasm and irony through the perception of intonational cues, around the age of five or six (Dews et al. 1996; Glenwright and Pexman 2010; Hancock et al. 2000; Harris and Pexman 2003; Keenan and Quigley 1999; Winner and Leekam 1991). In fact, the results of Capelli et al. (1990) show that children are unable to identify sarcasm without the presence of these intonational cues and when provided only with context, even when the context clearly conveys a nonliteral meaning. Contrary to these studies, several others conclude that intonation is more important later in the early stages of pragmatic development, around the age of eight (Ackerman 1983; Capelli et al. 1990). Looking more in detail regarding the effects of prosodic cues used by children in their acquisition of sarcasm, Glenwright et al. (2014) explore the effects of f0 manipulation on children's and adults' interpretation of sarcasm, including three degrees of $\mathrm{f} 0$ reduction. Their close examination of the gradient levels of f0 shows that five- and six-year-old children, as well as adult speakers, are more accurate in identifying the nonliteral meaning of sarcastic utterances when $\mathrm{f} 0$ contrasts are greater, suggesting that $\mathrm{f} 0$ is useful for both children and adults when differentiating sarcasm from sincerity. 
Few studies have explored the acquisition of sarcasm versus sincerity in secondlanguage (L2) speakers and even fewer have analyzed this in bilingual speakers, such as heritage speakers. Mandler (1979) suggests that L2 learners will interpret sarcasm first through knowledge of their L1 system. This is echoed by Ushakova's (1994) work on L2 development, where learners depend on their existing L1 semantic system in order to learn vocabulary from the L2 system. Kim (2014, p. 194) connects this idea to pragmatic functions: "If learners' conceptual systems operate based on their L1, the comprehension of sarcastic expressions and their meanings likely depends on the translation equivalents and usages existing in learners' L1 classification systems." Furthermore, comparisons of native speakers (NS) and non-native speakers (NNS) show differences in processing prosody, for example, in the identification of stress (Cutler et al. 1997; Dupoux et al. 1997). Results from these studies show that NNS may not be able to analyze prosodic cues in the same way as adult NS, ultimately creating a comprehension gap, given that intonation has been shown to be a significant factor in the identification of sarcasm. Furthermore, Peters et al. (2016) compare the ability of NS and NNS of English (NS of Arabic) to recognize sarcasm, based on both context and prosody, and find that when context and prosody are balanced, NNS perform more poorly than NS in the differentiation of sincere versus sarcastic speech and depend more on context rather than prosodic cues. In light of these inconsistent conclusions, Cheang and Pell (2013) suggest that the prosody of sarcasm is specific to language, and that L2 learners require training in order to effectively produce sarcastic speech. This is also supported by Chen and Jong (2015) in a study on Dutch learners of English, where speakers do not effectively produce sarcasm according to prosodic cues. These studies on sarcasm by L2 and bilingual speakers indicate a need for more research to determine how speakers use prosodic cues to differentiate sarcasm and sincerity. Furthermore, this work presents a new avenue into the study of the prosody-pragmatics interface of the speech of heritage speakers, in particular, the strategies used to convey sarcasm in both languages.

\subsection{Spanish Heritage Speaker Prosody}

Couched in the framework of the Autosegmental Metrical model (Ladd 2008; Pierrehumbert 1980) and the Spanish Tones and Break Indices framework (Sp_ToBI; Beckman et al. 2002; Face and Prieto 2007; Hualde and Prieto 2016), previous work on heritage speaker intonation has focused on the production of statements and questions to highlight features when compared to monolingual and other bilingual varieties. For example, in a study of intonation in Miami-Cuban bilinguals, Alvord (2010) shows that first- and third-generation speakers use a falling nuclear pattern for yes-no questions, which is to be expected for Cuban Spanish. Second-generation speakers, however, produce a final rise, which is more commonly observed in yes-no questions in American English. The findings suggest that this could be due to the social networks of the participants, among other factors, such as Spanish/English bilingualism and the influence of dialect contact. In the Mexican Spanish of Los Angeles (LA), Robles-Puente (2014) finds that speakers exhibit differing pitch accents and boundary tones across varied utterance positions and types, according to their time lived in LA and whether they were born in the US. Research on the intonation of HSS by Zárate-Sández (2015) shows that HSS declarative utterances pattern similarly to those of advanced L2 speakers. In addition, the intonational contours of HSS participants fall between those of monolingual English and monolingual Spanish control groups. Furthermore, when compared to monolingual Spanish speakers, Chicano HSS, as seen in Harris et al. (2015), convey new information through f0 manipulation rather than word order, which is typical of monolingual varieties of English, suggesting contact influence. Contributing to the body of research on language influence, a recent study on uptalk in HSS by Kim and Repiso-Puigdelliura (2021) compares the intonational contours of uptalk in heritage speakers of Mexican Spanish in Southern California and monolingual speakers of Mexican Spanish. Uptalk in HSS is often attributed to influence from English; however, the authors have found evidence of uptalk in monolingual Mexican Spanish as well. While the two groups show similar frequency in their use of uptalk, the respective 
intonational contours are quite different. According to the authors, the contours produced by HSS are more similar to patterns of uptalk in English, suggesting a possible influence from the majority language rather than existing features of monolingual Spanish. Also contributing to the area of research on language contact influence, Rao (2016) shows that HSS declarative intonation has a reduced phonological inventory when compared to the Mexican speakers in De-la-Mota et al. (2010); however, the interrogative intonation of HSS exhibits the same degree of variation as that of the Mexican speakers, although they employ different tonal targets. Conclusions explaining the variation in HSS production, reported by Rao (2016), point to the influence of language contact and sources of input (following Pascual y Cabo and Rothman 2012). In a study on the production of narrow focus in HSS, L2 learners, and monolingual Spanish speakers, Kim (2019) shows that in the speech of L2 learners, narrow focus is expressed through prosody, whereas monolingual Spanish speakers use word order. While these results are to be expected, given previous research on the topic, the HSS participants exhibit a combination of these two approaches, using both prosody and word-order manipulation to express narrow focus. These results suggest that HSS employ elements from their linguistic repertoire in both English and Spanish to communicate information structure. Moreover, these theories of bidirectionality and hybridity in heritage speaker pragmatics, as explored in the next subsection, could be used to explain this conclusion.

Taking into account methodological considerations in HSS prosody, Rao (2019) and Rao and Amengual (2021) both point out that a useful method of delving deeper into this issue is to conduct cross-generational studies with participants who are members of the same family. With such a pool of participants, one could gain insight into, for example, whether features of the source variety of adult immigrant parents are reflected in the speech of the subsequent generation, their heritage speaker children, whose primary HL input often comes from parents. Aziz et al. (Forthcoming) recently adopted this suggestion by taking inventory of the yes-no question intonational configurations of heritage speakers of Argentinian and Venezuelan Spanish, their adult immigrant parents, and a control group of Canadian English speakers, with all groups residing in Ontario, Canada. Their acoustic and statistical analyses reveal evidence of both the parents' Spanish and English at the word level (i.e., pitch accents) as well as English influence at the phrase level (i.e., boundary tones and phrase-final sequences of pitch accent + boundary tone), suggesting that pervasive contact with English, the societally dominant language, plays a stronger role overall in determining the shape of these HSS's yes-no question contours in the HL than does past and present parental input in the HL itself. In a study comparing HSS and bilingual immigrants, Colantoni et al. (2016) explore the use of different types of tasks to elicit data, including a reading task and a narration task. The reading task shows significantly different results between the two groups, but HSS and bilingual immigrants pattern similarly in the narration task. The authors conclude that, in order to elicit more authentic data, narration-type tasks are preferred.

\subsection{Spanish Heritage Speaker Pragmatics}

Research on the theoretical foundations of heritage language pragmatics (HLP) is in its incipient stages, but almost all work completed up to the present time points to the highly interdisciplinary nature of this field, including, but not limited to, areas of second language acquisition (SLA), bilingualism, sociolinguistics, and anthropology (Xiao-Desai 2019). Studies to date regarding sociopragmatic issues in heritage speakers are primarily production-based in nature and involve differing levels of formality and sociolinguistic variation in speech acts, such as requests, directives, impoliteness, disagreement, and complaints. In studies on requests and directives in Spanish-English bilingual children, both Walter (1981) and García and Leone (1984) report significant effects of setting and the gender of the addressee in their interactions, suggesting that bilingual children have a high level of awareness from a young age. Potowski (2007) explores the appropriateness of the requests of eighth-grade dual-immersion students in Chicago when compared to L2 Spanish 
students and Spanish-dominant recent arrivals. The study finds that requests produced by heritage speakers are more similar to those of the recent arrival group rather than the L2 Spanish learners, showing high "difference scores" in both oral and written requests between informal and formal contexts. In another study involving complaints, Elias (2013) finds that second-generation Mexican American bilinguals show more solidarity with their interlocutor in Spanish but a higher degree of deference in English, suggesting that speakers draw from two distinct pragmatic systems when making complaints. A multigenerational study on requests produced by Cubans and Cuban Americans in Miami, conducted by Gutiérrez-Rivas $(2008,2011)$, shows that when compared to first-generation speakers, thirdgeneration speakers, particularly female participants, are more likely to employ more indirect strategies that are characteristic of monolingual English speakers. The authors conclude that pragmatic acculturation can occur in an extended contact situation, where pragmatic features of the predominant culture begin to show some degree of influence. Furthermore, important studies of adult heritage requests and complaints from Pinto and Raschio $(2007,2008)$ show that the strategies used by heritage speakers to complete requests in Spanish pattern more closely with those that are characteristic of monolingual English speakers rather than those of monolingual Spanish speakers from Mexico. Similarly, with complaints, heritage speakers employ various mitigation tactics often found in monolingual English varieties when speaking Spanish; however, not all complaints mirror English patterns since the same heritage speakers also produce complaints that are more like the monolingual Spanish speakers from Mexico. According to the authors, hybridity in the production of HSS represents an "inbetweenness" of Spanish as a heritage language.

While detecting the precise source of language change-either internal or external-is unlikely, situations of language contact, as in the English-Spanish contact situation in the United States, can give rise to some developments that have already been observed in the Spanish language (Montrul 2012; Silva-Corvalán 1994, 2001). Given the relatively small body of research on the pragmatics of Spanish as a heritage language and the inconsistency of results, Pinto and Raschio (2008) synthesize recommendations for more research on specific topics, such as contexts in which heritage Spanish is similar to monolingual varieties of Spanish as well as monolingual varieties of English, and contexts in which heritage Spanish is significantly different from monolingual varieties of Spanish, monolingual English or both. In situations of extensive language contact, Blum-Kulka and Sheffer (1993) suggest that pragmatic features may be among the first to be influenced due to many factors; therefore, more research in this area is needed. Xiao-Desai (2019, p. 475) highlights the importance of considering the unique experiences of heritage speakers and the complex sociopragmatic factors that influence language production and perception. According to the author, key theoretical approaches to the study of pragmatic issues in HLP include bidirectionality and hybridity, the first of which highlights the "bi-directional influence between the societal and home language," and the second of which focuses on the ability and necessity of heritage speakers to draw from their linguistic repertoire in both languages to form a "hybrid knowledge base."

\subsection{Sociolinguistic Considerations}

More recent studies have pointed to the importance of considering sociolinguistic factors in the analysis of pragmatic meaning, including age, gender, age of arrival to the US, type of early bilingualism, and cultural identity.

An innovative study on the effects of sociolinguistic factors in the expression of sarcasm in online written communication by Oprea and Magdy (2020) finds that social factors play a significant role in the identification of sarcasm. For example, sarcasm that is expressed by females from the UK is more effective than that which is expressed by males in the US. In addition, sarcasm expressed by younger UK females was more effective than that by older UK females, whereas US males did not show a significant difference with regard to age. While the work of Oprea and Magdy (2020) focuses on online exchanges, their conclusions regarding the significance of sociolinguistic variables such as gender 
and age on the effectiveness of sarcasm directly motivate the analysis of these variables in the current study. Rao and Amengual (2021) have also identified age as a variable that merits increased investigation in studies on the sounds systems of HSS. Furthermore, Froemming and Rao (2021) explore the extent to which the sociolinguistic factors of age, gender, social class, and level of education motivate tritonal intonation patterns that are found in broad-focus declaratives in Cuenca Spanish. Results show that while participant age is not as salient, participant gender and socioeconomic class do yield particularly salient conclusions, in that females and members of lower socioeconomic status employ the tritonal pitch accent almost two times as much as male participants and those members of the higher socioeconomic class. While this study does not deal with HSS, it is included in this section because it is an example of a recent study from a region with historical and current language contact, one that revolves around the effects of sociolinguistic factors on one aspect of prosody.

In addition to gender and age as relevant sociolinguistic variables, Alvord (2010) states that age of arrival to the US is a relevant factor since this is likely indicative of the age at which English acquisition began. The earlier the arrival, the more likely it is that the speaker would exhibit intonational patterns that are associated with English. Related to the age at which a person begins the acquisition of English is the length of time they have lived in a language-contact environment; for example, a longer time spent in the US is also equivalent to a longer time spent acquiring English in an English-dominant environment; thus, there is a greater likelihood again that the speaker will exhibit intonational patterns that are associated with English. Taking this into consideration, in Alvord's (2010) study on the absolute interrogative intonation patterns in of Miami Cuban Spanish as produced by bilingual speakers of English and Spanish, participants who arrived in the US as children, as well as those that have lived in the US for some time, consistently produce absolute interrogatives with a rising-intonation pattern that is typical of absolute interrogatives in English, whereas adult, recent arrivals to the US produce absolute interrogatives with a falling-intonation pattern that is typical of Cuban Spanish. Alvord (2010) concludes that while the rising-intonation pattern can also be found in other varieties of Spanish, it is likely that the rising pattern used by childhood arrivals and those who have lived in the US for some time is due both in part to contact with English and to contact with other Spanish varieties with a rising-intonation pattern.

Another variable that has been shown to affect the acquisition of phonological alternations is type of early bilingualism: simultaneous bilinguals are those who learn two languages at the same time from birth, and sequential bilinguals are those who learn one language from birth and begin acquiring their L2 when beginning in the formal education system in the majority language. Amengual's (2019) acoustic analysis of the degree of lenition of voiced occlusives in intervocalic position included three participant groups: English-dominant-L1 English-L2 Spanish learners, Spanish-English early simultaneous bilinguals, and Spanish-English early sequential bilinguals. Results differ among the early Spanish-English bilinguals according to the degree of lenition, where sequential bilinguals produce a higher degree of lenition than simultaneous bilinguals. This conclusion indicates that exposure to the minority language during early childhood plays a pivotal role in the continuation of phonological features into adulthood. This is further evidenced by RoblesPuente's (2014) study on the comparison of intonational contours used by Spanish and English monolingual speakers with adult early bilinguals born in Mexico, child/adolescent Los Angeles-born bilinguals and adult late bilinguals. In this study, all bilingual groups show significantly different intonational contours in English from the control group, meaning that Mexican Spanish intonation patterns are evident in their English productions. However, when speaking Spanish, the bilinguals born in LA, and adult late bilinguals do not differ from the Spanish control group. The adult early bilinguals, on the other hand, do show significantly different intonational contours; according to the author, this may indicate an "intermediate intonational behavior." This conclusion is of particular relevance 
to the current study in that the place of birth, e.g., Mexico vs. the USA, could be a significant factor in determining prosodic patterns in both English and Spanish.

Kissling (2018) delves further into the sociocultural background of HSS, teasing apart the varied cultural identities of HSS that contribute to the acquisition of phonology and phonetics. For example, HSS in the study are further separated into two distinct cultural subgroups, one with a strong sense of cultural heritage and one without. The HSS in the first subgroup produce rhotic segments that are identical to those of native monolingual speakers and long-term immigrants, whereas HSS that do not have a strong Latino/Hispanic connection produce rhotics that are more similar to those of L2 speakers. Kissling (2018) suggests that cultural identity could indirectly explain differences in speech production.

\subsection{Current Agenda}

The body of research summarized above provides the foundation and motivation for the current study. Therefore, the two research questions for the current study are the following: How are the attitudes of sarcasm and sincerity, as well as the effects of gender, bilingual type, place of birth, language dominance, and age, manifested through f0 mean, f0 range, and speech rate outcomes in the production of identical strings of words in Spanish and English by bilinguals? How is the attitudinal contrast in question exhibited across members of the same family that are from different generations and/or who display different language dominance patterns? This paper fills a research gap by combining previous research on sarcasm and sincerity, the prosodic manifestation of sarcasm and sincerity in HSS, the acquisition and development of pragmatics, and the interface between prosody and pragmatics in HSS. It allows us to see how different language experiences and social variables influence prosodic outcomes in the expression of these attitudes, in order to identify the possible convergence or divergence of two prosodic-pragmatic systems and factors that might play a role in determining such trends.

\section{Methods}

This section provides the background profiles of our English-Spanish bilingual participants, information on our data collection process, and the acoustic analysis techniques that we employed in order to address our research questions.

\subsection{Participants}

A total of 19 English-dominant HSS, who were part of a larger pool of bilingual speakers that completed a series of tasks besides just the one used in this study, were recruited to participate through the social network of a research assistant (see Appendix A for detailed profiles of these speakers). Participants were not grouped in a specific way; rather, they were treated as individual units who we coded based on the possible categories of each of our independent variables. They had all resided in the Midwest region of the USA (i.e., the Chicago area of Illinois or southern Wisconsin) for the majority of their lives. As of the time of recording, they ranged in age from 18 to $52(M=36, S D=12)$. Based on the information provided by our research assistant concerning factors such as past life experiences, current life activities, and social networks, we opted to create a categorical method of coding their age (i.e., 18-30-year-olds, and 30 and older), which would, in turn, facilitate the statistical exploration of this variable's effects. At the time of data collection, 7 participants were classified as $18-30$ and 12 as 30 and older. Regarding gender, 12 are female and 7 are male. Concerning our other variables of interest, 13 were born in the USA and 6 were born in Mexico but came to the USA during their childhood. Finally, 11 were categorized as simultaneous bilinguals (i.e., Spanish and English at home before entering school, typically at age 5) and 8 as sequential bilinguals (i.e., only using Spanish at home prior to starting school). Given that the research assistant who worked directly with the participants knew them all (including the additional individuals incorporated into the family-level analysis) and was aware of our independent variables of interest, she was 
able to gather all this information informally, without the use of a standardized language history questionnaire.

The family-level analysis involved 10 participants; the 7 English-dominant individuals were also included in the aforementioned set of HSS, while the remaining 3 were Spanishdominant (see Appendix B for details about all these family members). Two of the Spanishdominant speakers were the parents (ages 81 and 73), 7 of the participants were their children (ages 40-50; 4 females, 3 males), 1 of whom assessed herself as Spanish-dominant, and 1 of the participants was their grandchild (age 18). The parents and their 6 oldest children were born in Mexico, while their youngest child and grandchild were born in the USA. Lastly, the 5 oldest children were classified as sequential bilinguals, while the youngest 2 and the grandchild were considered simultaneous bilinguals.

\subsection{Materials}

In order to quantify the variable language dominance in our set of bilingual participants, we requested that they all complete the Bilingual Language Profile (BLP; Birdsong et al. 2012). This is a standardized self-assessment of dominance, which is broken down into four modules: language history, language use, language proficiency, and language attitudes. The final output of a series of scalar questions is a score ranging from -218 to +218 ; each pole of this continuum would represent a monolingual in one language or the other $(-218=$ Spanish, $+218=$ English $)$, while a score of 0 would point to a completely balanced bilingual (i.e., not dominant in either language).

In order to elicit the production of sarcastic and sincere attitudes in both the languages of our participants, we adopted the task designed and implemented by Rao (2013) for Spanish. In this task, which we ran in both Spanish and its English equivalent, participants read to themselves a hypothetical context that primed sarcasm or sincerity, then saw a scripted response, thought about how they would produce it in a real interaction based on the hypothetical context, and were then recorded when producing it. For both Spanish and English, 15 scripted responses were each contextualized in two distinct ways that allowed us to gather identical strings of words produced as sarcastic and sincere by all participants in both of their languages (with the exception of the parents in the family-level analysis, who only completed the task in Spanish). In summary, each HSS generated a set of 60 recorded responses: 15 scripted utterances $\times 2$ attitudes $\times 2$ languages $=60$ ). The 4 sample items (1-4, below) demonstrate the process just described.

(1) Eliciting sarcasm in English Hypothetical context: You're on an airplane and your friend says, "They're going to serve us food now." The food doesn't smell good, and the flight crew hasn't treated you well. Scripted response: All of a sudden, I'm very hungry.

(2) Eliciting sincerity in English Hypothetical context: You're on an airplane and your friend says, "They're going to serve us food now." The airline has a reputation for serving delicious food. Scripted response: All of a sudden, I'm very hungry.

(3) Eliciting sarcasm in Spanish Hypothetical context: En un avión, tu amigo te dice, "Nos van a servir comida." La comida no huele bien y la tripulación no te ha tratado bien. Scripted response: De repente tengo mucha hambre.

(4) Eliciting sincerity in Spanish Hypothetical context: En un avión, tu amigo te dice, "Nos van a servir comida." La aerolinea tiene una reputación de servir comida rica. Scripted response: De repente tengo mucha hambre.

\subsection{Acoustic Analysis}

Praat software (Boersma and Weenink 2020) was used to carry out our measurements of speech rate (syllables/second), f0 mean, and f0 range for all data across both of our attitudinal and language conditions. In order to calculate the speech rate for each task item, the duration of each utterance was isolated, the number of syllables articulated was counted, and then the latter was divided by the former to obtain a speech rate measurement. Regarding $\mathrm{f0}$, the mean of each recorded item was extracted by isolating the utterance and 
querying "get pitch" in Praat, whereas for range, the high and low f0 points across each production were identified, and the latter were subtracted from the former.

\subsection{Statistical Analysis}

We used linear mixed-effect models (Gelman and Hill 2006) to compare the prosody of the sarcastic and sincere attitudes of our 19 English-dominant bilinguals, speaking English or Spanish, in terms of three features of interest: speech rate, $\mathrm{f0}$ mean, and $\mathrm{f} 0$ range. Then, we looked into whether participants from the same family patterned similarly, to tap into potential source-input effects.

In our analysis, we treated each English-dominant speaker as an experimental unit for whom repeated measurements were recorded when reading 15 different base sentences with sincere or sarcastic attitudes, and in Spanish or English. We used a linear mixed-effect model to capture the correlation among those repeated measurements for each participant and to reflect participant heterogeneities. The models we fitted consisted of both fixed effects and random effects. Our fixed effects of interest included the main effects of attitude (i.e., sincerity or sarcasm), language (i.e., English or Spanish), dominance (i.e., low, middle, or high, based on BLP scores (see Section 4.1.1)), gender (i.e., male or female), bilingual type (i.e., simultaneous or sequential), place of birth (i.e., USA or Mexico), and age (i.e., 18-30 or 30 and older), as well as the interactions of attitude, language, and the other variables. We included the random effects of participant and sentence. Because the f0 range has a heavy tail, we applied a logarithmic transformation before model fitting. We also removed one outlier (participant 25, reading sentence 1 sarcastically in English).

For each one of the three features, we started with a full model fitted in $\mathrm{R}$ using the package lme4, with all the fixed effects of interest and random effects, then we performed a backward elimination of non-significant terms, using the lmerTest package in $\mathrm{R}$ to obtain a more parsimonious model. The resulting three models all converged. In addition, we applied a series of model diagnostic tools to check the underlying assumptions. We found that the models fitted the data well and were robust in terms of influential observations from examining residual plots, and the change in coefficients with and without influential observations. We checked the normality of residuals using quantile-quantile plots and found that this was plausible for speech rate but may have been violated for f0 mean and $\mathrm{f} 0$ range. Therefore, in addition to calculating the confidence intervals (CIs) using the profile likelihood approach (Bates et al. 2015), we also checked by calculating the CIs using the percentile bootstrap, which is robust in terms of violation of the normal residual assumption, finding good agreement. We provide $\mathrm{R}$ codes for all analyses reported in our supplementary material.

\section{Results}

\subsection{Descriptive Statistics \\ 4.1.1. BLP}

We confirmed the English-dominant nature of our 19 HSS through their positive BLP scores, all of which are plotted in Figure 1 (range: $36-129.1, M=79.6, S D=30.4$ ). This figure was useful because it allowed us to code our HSS, based on three dominance-based classifications; that is, the five participants below the lower quartile were deemed to be the least English-dominant (i.e., the relatively most balanced bilinguals), the nine within the upper and lower quartiles could be labeled as mid-English-dominant, and finally, the five above the upper quartile were categorized as the most English-dominant (i.e., the relatively least-balanced bilinguals).

Regarding the family-level analysis, on the one hand, the seven English-dominant participants ranged in BLP scores from 36-129.1 (i.e., the least English-dominant and most English-dominant individuals from the pool of 19 HSS were both part of this family), while their mean and standard deviation were 91.4 and 35.4, respectively. On the other hand, the three Spanish-dominant members of the family in question generated a wide range of BLP scores: -183.1 (mother), -69.6 (father), and -15.7 (one of the daughters). From these, we 
can see that the mother trends toward the monolingual Spanish pole, while the daughter views herself as fairly close to a balanced bilingual.

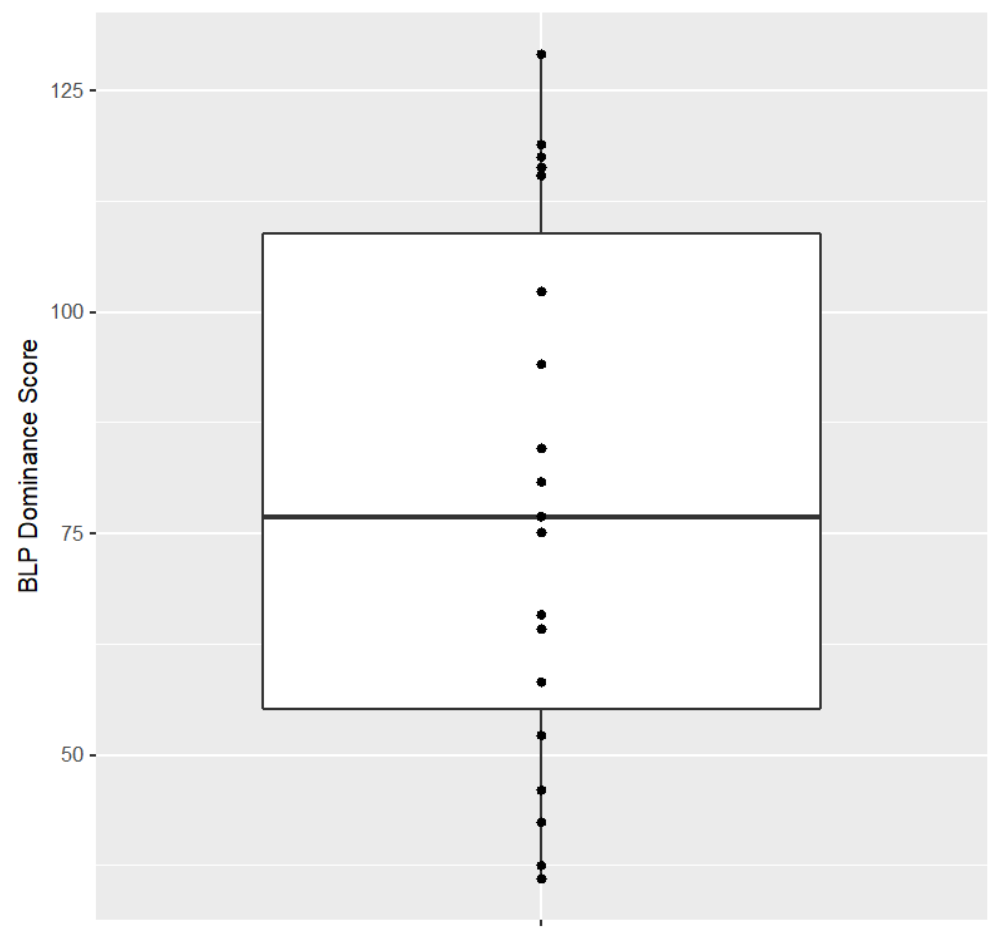

Figure 1. Box plot of BLP scores across all 19 English-dominant participants.

\subsubsection{Acoustic Measures}

Figure 2, the corresponding speech rate and $\mathrm{f} 0$ measurements of which are contained in Table 1, provides sample contours tied to the productions of "All of a sudden, I'm very hungry" and "De repente tengo mucha hambre" (same meaning in both languages) by a female speaker (ENG25). The four productions are classified as follows: (a) sarcasm in Spanish, (b) sarcasm in English, (c) sincerity in Spanish, and (d) sincerity in English.

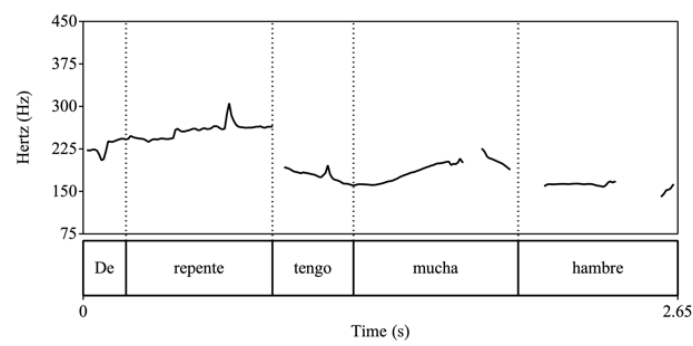

(a)

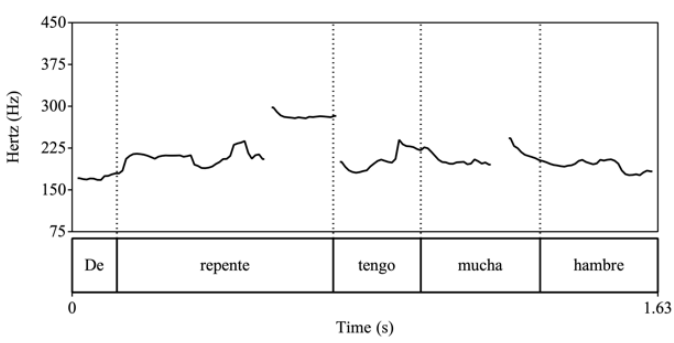

(c)

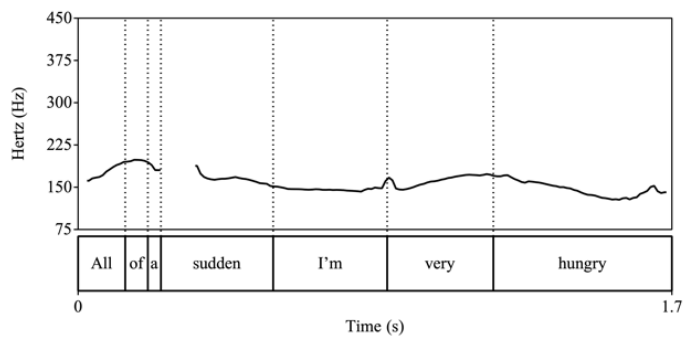

(b)

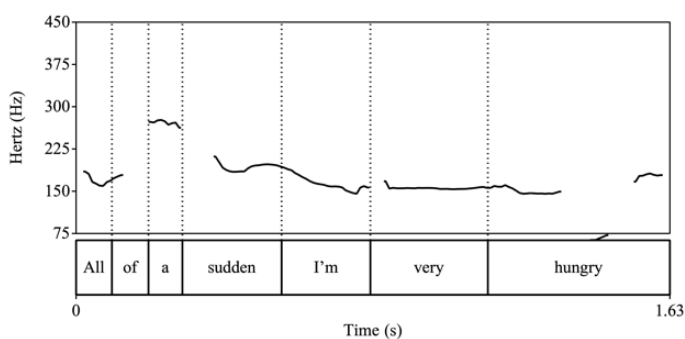

(d)

Figure 2. Sample contours produced by a female speaker, illustrating the attitudinal and language conditions of interest. Panels $(\mathbf{a}, \mathbf{b})$ signal sarcasm, while panels $(\mathbf{c}, \mathbf{d})$ convey sincerity. 
Table 1. Key observations from Figure 2.

\begin{tabular}{cccccc}
\hline Panel & Attitude & Language & Speech Rate (syll/s) & f0 Mean (Hz) & f0 Range (Hz) \\
\hline 2a & Sarcastic & Spanish & 3.8 & 204.3 & 119.8 \\
2b & Sarcastic & English & 5.9 & 166.6 & 68.1 \\
2c & Sincere & Spanish & 5.5 & 218.0 & 122.7 \\
2d & Sincere & English & 6.1 & 182.4 & 122.3 \\
\hline
\end{tabular}

When comparing attitude both within and across languages, certain trends arise from this particular sample set of productions, laid out to demonstrate how the acoustic analysis of the data set was handled. The next section will reveal whether or not these patterns held across the board, and if so, whether or not they achieved statistical significance. Concerning speech rate, sarcasm is produced more slowly than sincerity, and the English rate is faster than that of Spanish. For fo mean, sarcastic articulations occur at a lower f0 level, overall, and the Spanish mean is higher than that of English. Finally, the outputs for f0 range are similar in both Spanish attitudinal conditions and in the sincere productions of both languages, with the outlier being sarcasm in English, where this variable exhibits compression.

\subsection{Inferential Statistics}

\subsubsection{Speech Rate}

The model for speech rate takes the following form:

$$
\text { Speech rate }=\beta X+b Z+\epsilon
$$

where $\beta$ collects all the fixed effects, $X$ is a vector including the intercept, attitude, language, gender, age (18-30 or 30 and older), dominance (low, median, or high), two-way interactions between attitude and language, attitude and age, language and gender, language and age, and language and dominance, $b$ collects all the random effects, and $Z$ is a vector of indicators for participants and sentences.

Figure 3 visually presents the interactive effects that are statistically significant at a 0.05 significance level. Taking the sarcastic attitude and speaking in English as the baseline group, the linear mixed-effects model finds that a sincere attitude is associated with a 0.25 faster speech rate (95\% CI, 0.15 to 0.35 ), and speaking in Spanish is associated with a 0.30 slower speech rate ( $95 \% \mathrm{CI}, 0.19$ to 0.40$)$; both are largely driven by the effect among the seven participants aged 18-30. Specifically, for these younger participants, sincere speech is associated with a 0.30 faster speech rate (95\% CI, 0.12 to 0.49$)$, and speaking in Spanish is associated with a 1.18 slower speech rate (95\% CI, 0.87 to 1.50). In contrast, we observed that neither attitude nor language significantly affected speech rate for the 12 participants who were more than 30 years old. For both age groups, a sincere attitude increased the speech rate more when speaking in English, compared to when speaking Spanish $(\beta=0.37$, 95\% CI, 0.17 to 0.56). Moreover, the linear mixed-effects model showed that the seven male participants' English speech was 0.53 faster than the female participants' English speech (95\% CI, 0.31 to 0.76); English speech for the nine participants with a middle BLP score was 0.31 slower than the other two groups (95\% CI, 0.06 to 0.56$)$. None of the other variables were found to significantly modify the effects of attitude and language on speech rate. 

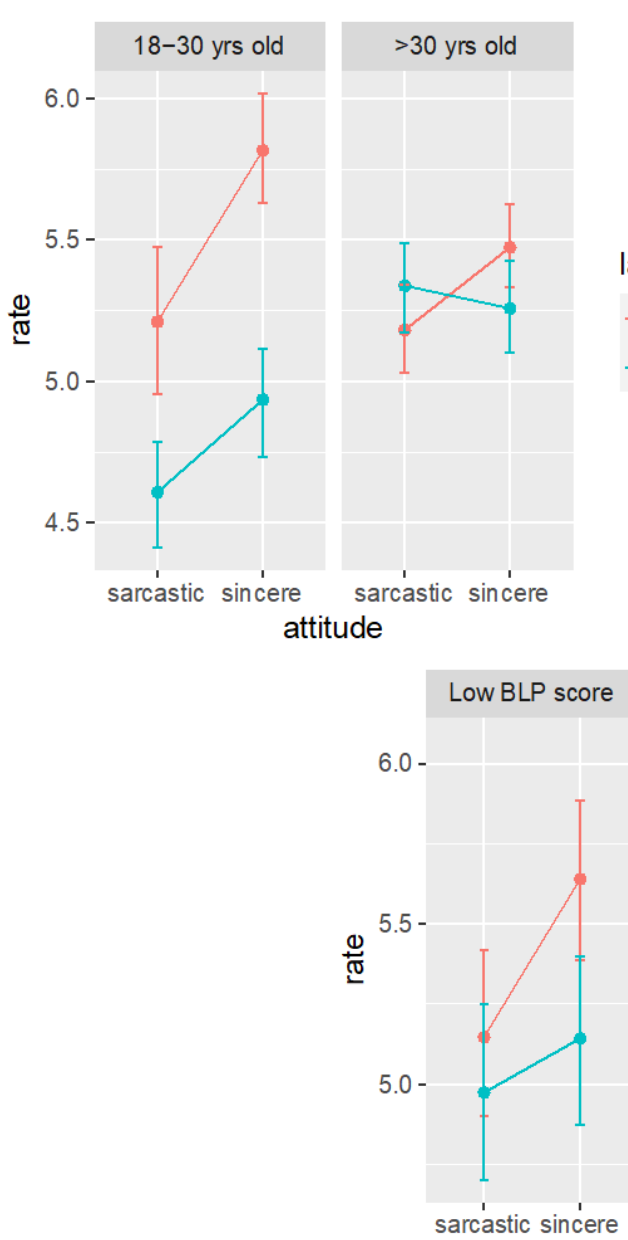
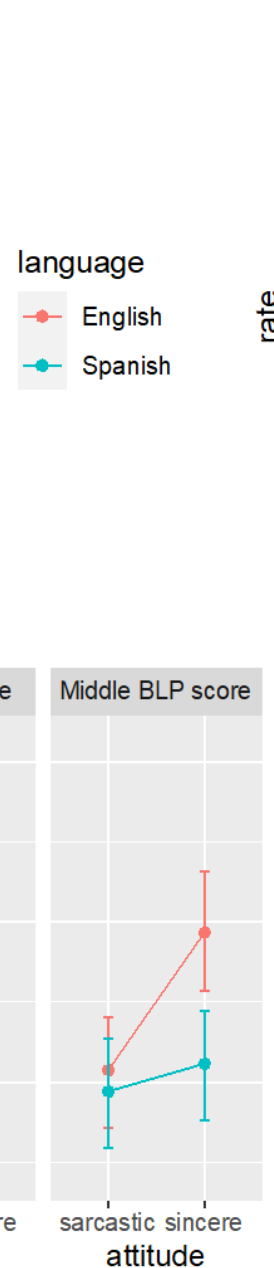

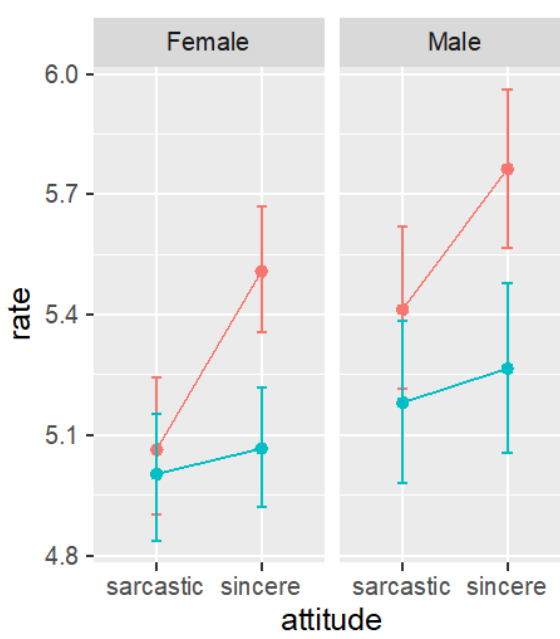

language

$\rightarrow$ English

$\rightarrow$ Spanish

Figure 3. The two-way interactive effects of attitude and language on speech rate, stratified by age (top left), gender (top right), and dominance (bottom), respectively. The solid points are the means, and the error bars are the bootstrapped standard errors.

\subsubsection{F0 Mean}

The model for the first measure of f0, mean, takes the following form:

$$
\mathrm{f} 0 \text { mean }=\beta X+b Z+\epsilon
$$

where $\beta$ collects all the fixed effects, $X$ is a vector including the intercept, attitude, language, gender, bilingual type, age (18-30 or 30 and older), dominance (low, median, or high), two-way interactions between attitude and language, attitude and bilingual type, attitude and age, language and age, language and dominance, and the attitude-language-age threeway interactions, while $b$ collects all the random effects, and $Z$ is a vector of indicators for participants and sentences.

Taking the sarcastic attitude and speaking in English as the baseline group, the linear mixed-effects model showed that a sincere attitude was associated with a 5.69 larger f0 mean (95\% CI, 3.65 to 7.74), and speaking in Spanish was associated with an 8.39 larger f0 mean ( $95 \% \mathrm{CI}, 6.34$ to 10.44$)$. Female participants had a 71.06 larger f0 mean compared to male participants ( $95 \%$ CI, 54.81 to 87.31 ). Figure 4 visually presents the interactive effects that were statistically significant at a 0.05 significance level. Specifically, speaking sincerely was associated with a 6.20 larger f0 mean $(95 \%$ CI, 1.50 to 10.91) for the seven participants aged 18-30 years old when speaking in English and Spanish, and for the 12 participants aged more than 30 years old, when speaking in English; the effect of a sincere attitude on $\mathrm{f0}$ mean for the 12 participants who were more than 30 years old when speaking Spanish is 
significantly smaller ( $\beta=4.66,95 \% \mathrm{CI}, 0.21$ to 9.10 ). This reveals a significant three-way interaction among attitude, language, and age. Moreover, a sincere attitude increased f0 mean more for the eleven participants whose bilingual type was simultaneous, compared to the rest, whose bilingual type was sequential ( $\beta=4.58,95 \% \mathrm{CI}, 0.07$ to 9.09 ). Finally, the nine middle-BLP-score participants' Spanish speech had an 8.53 larger f0 mean compared to their English speech (95\% CI, 3.39 to 13.68), while there was no significant language effect on $\mathrm{f0}$ mean for the other two dominance groups. None of the other variables were found to significantly modify the effects of attitude and language on f0 mean.
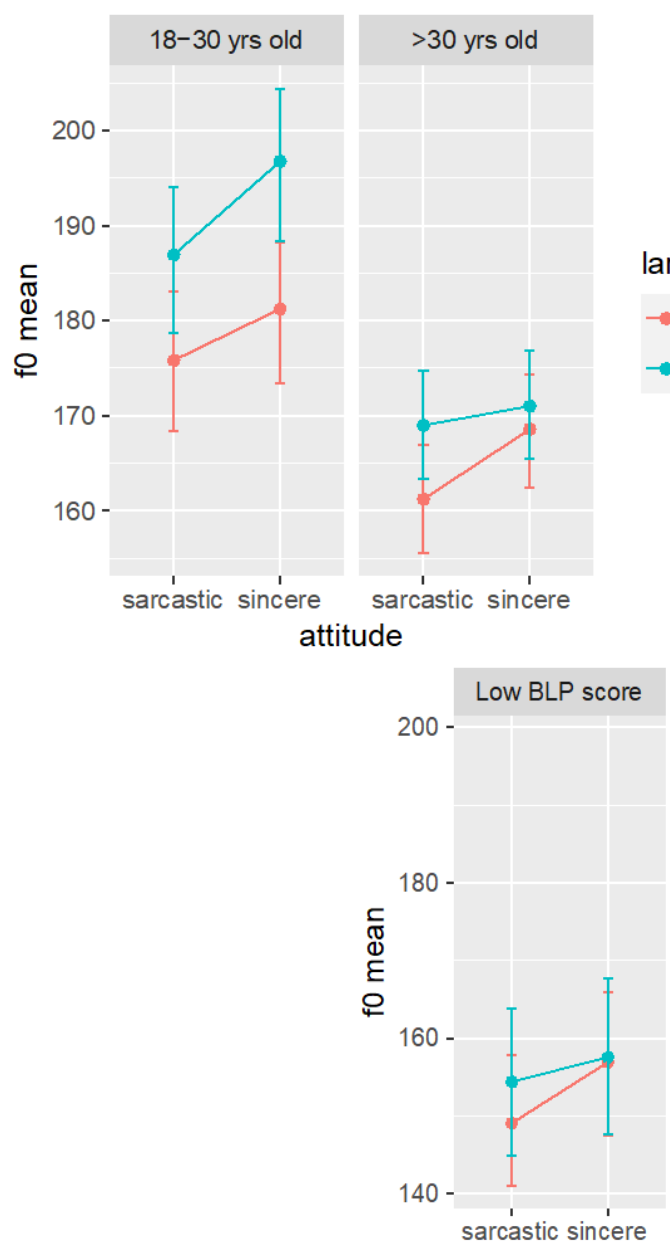
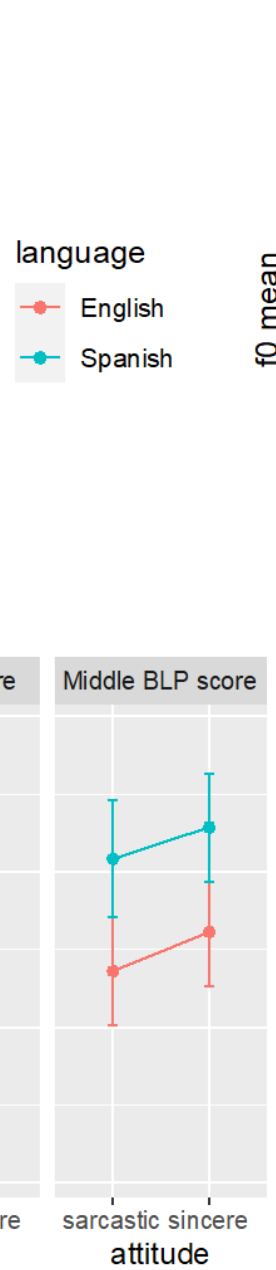

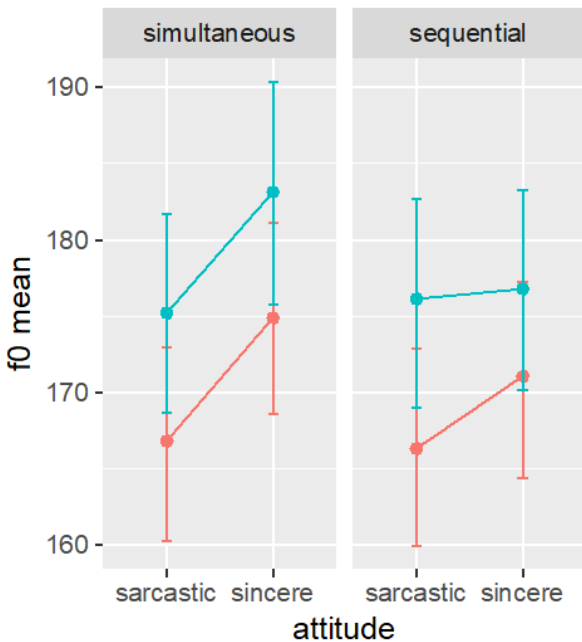

attitude language

$\rightarrow$ English

$\rightarrow$ Spanish

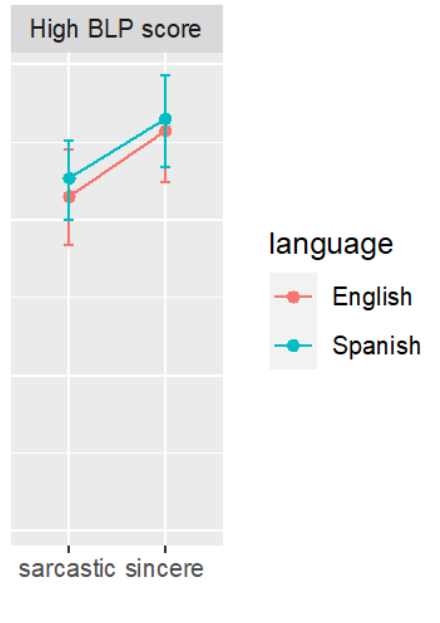

Figure 4. The two-way interactive effects of attitude and language on $\mathrm{f} 0$ mean, stratified by age (top left), bilingual type (top right), and dominance (bottom), respectively. The solid points are the means, and the error bars are the bootstrapped standard errors.

\subsubsection{F0 Range}

The model for the f0 range takes the following form:

$$
\log (\mathrm{f} 0 \text { range })=\gamma X+b Z+\epsilon
$$

where $\gamma$ collects all the fixed effects, $X$ is a vector including the intercept, attitude, language, gender, bilingual type, dominance (low, median, or high), two-way interactions between attitude and bilingual type and attitude and dominance, $b$ collects all the random effects, $Z$ is a vector of indicators for participants and sentences. We report the exponentiated regression coefficients minus one and multiplied by 100, which gives the percent increase in $\mathrm{f} 0$ range. 
Taking the sarcastic attitude and speaking in English as the baseline group, the linear mixed-effects model showed that a sincere attitude was associated with a $13.6 \%$ increase in $\mathrm{f} 0$ range (95\% CI, $8.4 \%$ to $19.2 \%$ ), and speaking in Spanish was associated with an $8.9 \%$ increase in f0 range (95\% CI, 3.9\% to $14.2 \%)$. Female participants had a $92.4 \%$ larger f0 range compared to male participants (95\% CI, $57.4 \%$ to $135.3 \%$ ). Figure 5 visually presents the interactive effects that were statistically significant at a 0.05 significance level. Specifically, a sincere attitude increased the $\mathrm{f} 0$ range more for the eight participants whose bilingual type was sequential, compared to the rest, whose bilingual type was simultaneous $(\beta=11.4 \%$, $95 \%$ CI, $1.0 \%$ to $22.9 \%$ ). Finally, a sincere attitude was associated with a $19.6 \%$ larger f0 range for the five high-BLP-score participants (95\% CI, 8.3\% to 32.2\%), while there was no significant attitude effect on $\mathrm{f} 0$ range for the other two dominance groups. None of the other variables were found to significantly modify the effects of attitude and language on f0 range.
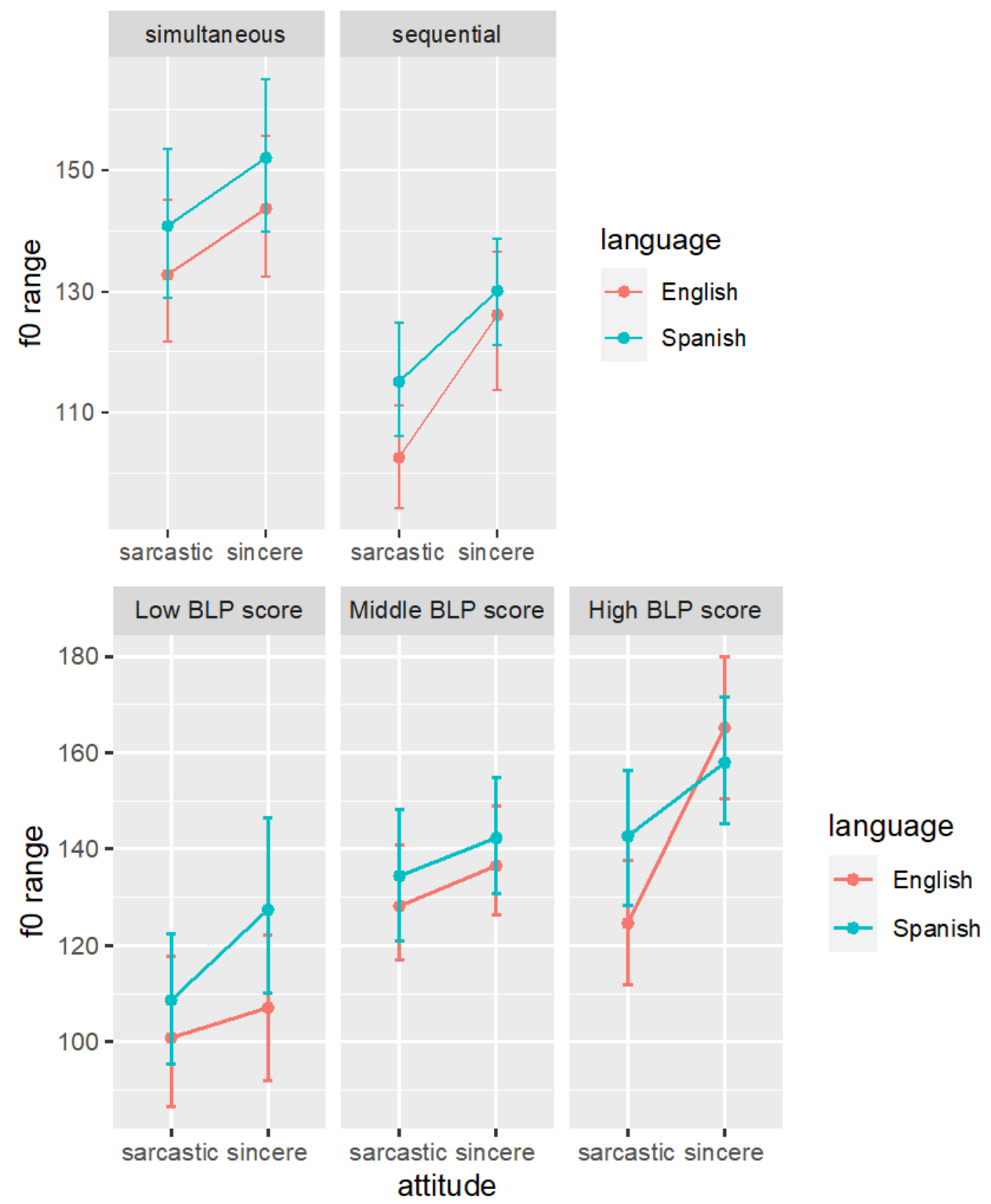

Figure 5. The two-way interactive effects of attitude and language on $\mathrm{f} 0$ range, stratified by bilingual type (top) and dominance (bottom), respectively. The solid points are the means, and the error bars are the bootstrapped standard errors. 


\subsubsection{Family Effect}

In the final piece of our analysis, the question that we set out to answer is whether or not members in the same family but in different generations and/or with a different language dominance pattern similarly when speaking with sincere and sarcastic attitudes. The larger dataset (which goes beyond just HSS) that we drew upon to scrutinize family effects contained ten members of one family, seven of whom are English-dominant speakers and three of whom are Spanish-dominant. Since two Spanish-dominant speakers in this family are not proficient in English, we restricted our family-level analysis to Spanish data. Figure 6 plots the effect of attitude on speech rate, $\mathrm{f} 0$ mean, and $\mathrm{f} 0$ range for participants in this particular family.
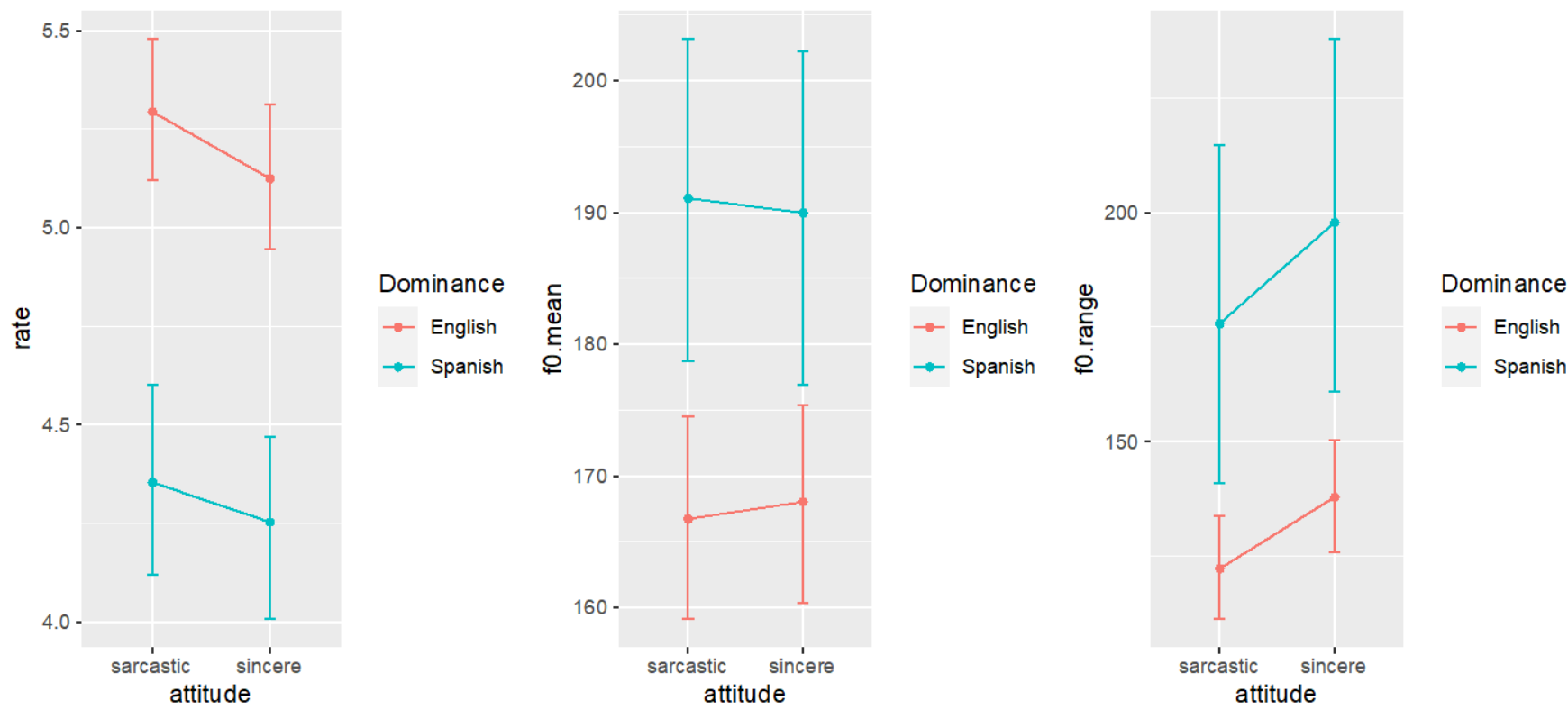

Figure 6. Mean and standard errors for speech rate, f0 mean, and f0 range when speaking Spanish among participants in one particular family. The red lines correspond with English-dominant speakers and the blue lines with Spanish-dominant speakers.

From Figure 6, an interesting observation is that, across our other participants (and in previous research), speaking sincerely often tended to occur at a faster speech rate, but, in this particular family, speaking sincerely clearly exhibited the opposite trend. The effect of attitude on $\mathrm{f} 0$ mean and $\mathrm{f} 0$ range was also very similar for English-dominant and Spanish-dominant speakers in this family. Formally, we fitted linear fixed-effect models for these three dependent variables for members within this particular family, and we found no significant differences between the effects of attitude on speech rate, f0 mean, and f0 range for the seven English-dominant speakers versus the three Spanish-dominant speakers. This evidence suggests that members within a family pattern similarly.

\section{Discussion}

This study set out to fill a gap in the previous literature on HSS (and heritage speakers in general) - regarding the effects of intended pragmatic meaning on the production of suprasegmental aspects of speech-by examining the effects of sarcasm and sincerity in both languages of participants (i.e., English and Spanish) on speech rate, f0 mean, and f0 range, while also looking into potential interactions with a series of variables tied to participant background, as motivated by previous literature on HSS sound systems.

Table 2 summarizes the significant main effects and interactions for each of the three sentence-level dependent variables under investigation.

The fact that attitude and language appear to be significant for all three dependent variables is evidence of our HSS employing a particular set of distinct prosodic strategies 
to convey pragmatic nuances across their bilingual communicative repertoire. We will use the remainder of this subsection as a platform to explore in detail the implications of the results succinctly summarized in Table 2. First, it is worth pointing out that, interestingly, the only independent variable included in our analysis that does not appear significant in any way is the place of birth; that is, the fact of HSS being born in the USA or in Mexico does not influence the communication of sarcasm vs. sincerity in English or Spanish. Therefore, it does not appear that exclusive exposure to the HL during a portion of one's early childhood in Mexico was a crucial driver of the bilingual prosody-pragmatics issue examined here, perhaps because the participants born in Mexico are all on the older end of our age continuum (aged in the 40s and 50s), meaning that it is possible that the drastic imbalance between years in Mexico vs. the USA suppressed any potential effects of their handful of pre-school-age years in Mexico. Furthermore, even though the sarcasm vs. sincerity contrast may be heard by children prior to school age, they do not clearly tease apart these pragmatic intents and actually use them until well into their school years (Glenwright and Pexman 2010), which is a pivotal difference between the condition explored here and, for example, segmental phonology, where early childhood exposure to an HL has consistently been shown as helping to shape the phonology of this language in adulthood. In the case of all our participants, regardless of their place of birth, this would mean that the attitudinal contrast in question became active at a point when they had already had intense exposure to English and were presumably already Englishdominant. This implies that the potential early overhearing of sarcasm vs. sincerity in Spanish is, overall, less influential than the societally and educationally dominant language during school years when predicting bilingual Spanish-English prosodic signaling of this pragmatic contrast in adult HSS. We use this premise as a lens through which to expound the remainder of our implications in this section.

Table 2. Summary of significant effects.

\begin{tabular}{ccc}
\hline Dependent Variable & Main Effects & Interactions \\
\hline & & Attitude $\times$ Language \\
Speech rate & Attitude $\times$ Age \\
& Language & Language $\times$ Age \\
& & Language $\times$ Gender \\
& Language $\times$ Dominance \\
f0 mean & Attitude & Attitude $\times$ Language $\times$ Age \\
& Language & Attitude $\times$ Bilingual type \\
& Gender & Language $\times$ Dominance \\
f0 range & Attitude & Attitude $\times$ Bilingual type \\
& Language & Language $\times$ Dominance \\
\hline
\end{tabular}

By comparing just our Spanish sentence-level prosodic results for HSS to those reported by Rao (2013) for adult-immigrant bilinguals, we gain further insight into the prosodic-pragmatic outcomes in the speech of these two speaker profiles. While the sets of variables examined in each study are distinct, as are the statistical techniques implemented, the task is identical. Both studies demonstrate that a slower speech rate and a lower f0 mean are linked to sarcasm, which aligns with the bulk of previous cross-linguistic literature already outlined. Future considerations regarding heritage (Spanish) prosodic-pragmatic outcomes should also include phonological analysis and additional, word-level prosodic measurements, similar to those in Rao (2013), to highlight localized changes in different speaker profiles (e.g., see Mennen et al. 2012, 2014 for notes on global versus local measures of f0 range). On the other hand, regarding gender, Rao's study finds that males employ f0 range to contrast sarcasm vs. sincerity to a larger degree; however, in the current study, f0 range does not display such an effect in the Spanish data (e.g., no significant three-way interaction of attitude $\times$ language $\times$ gender for $\mathrm{f} 0$ range). While females expanded their $\mathrm{f} 0$ range when compared to males in both studies, male adult-immigrant speakers of Spanish 
do this significantly more in sincere conditions, whereas this is not the case for male HSS. Clearly, while both datasets shared some presumably universal similarities, a potential set of differences has been opened up through the gender variable (see Passoni et al. 2018 for another example of gender-based bilingual f0 variation). Future research could work toward expanding on this point by running the same set of inferential statistical models on data coming from adult immigrants, among other speaker pools, all of whom could complete the same task used here. This would allow us to learn more about how, for example, varying childhood and adolescent experiences with Spanish impact the prosody of attitude in adults.

A crucial takeaway from the significant effects that are detailed in Section 3 and reviewed in Table 2 is the low number of two- and three-way interactions involving both attitude and language. This is noteworthy because if we were to claim that our HSS have developed completely separate sets of bilingual suprasegmental strategies to convey sarcasm vs. sincerity, then we would observe more ways in which, for example, sarcasm or sincerity are expressed differently in Spanish or English. Instead, what we generally see is that attitude has an effect across both languages, and language has a distinct effect across both attitudes, but they do not interact in as many ways as they potentially could, given our broad range of dependent variables. From the former, we can ascertain that attitude impacts productions in both languages fairly similarly, while the latter tells us that language effects resemble one another across both attitudes. In essence, for the three dependent variables, the factors of sarcasm and sincerity move their values similarly up or down in both English and Spanish, and the factors of English and Spanish move their values up or down similarly within the sarcastic and sincere conditions. Visually, this is why we see several sets of parallel lines in Figures 3-6.

In the two cases where we did witness interactions involving attitude and language (i.e., speech rate and $\mathrm{f} 0$ mean), we observe that sincerity created a stronger influence. This means that the small amount of evidence pointing to attitude-based prosodic divergence in our bilinguals is linked to literal rather than ironic intents. In exploring the noteworthy case of $\mathrm{f0}$ mean and its three-way interaction of attitude $\times$ language $\times$ age, we note that the increase in $\mathrm{fO}$ activity that was associated with both languages in the younger age group makes sense, given that such increases are more typical in younger vs. older age groups (see, e.g., Skoog Waller and Eriksson 2016). On the contrary, in the older group, a similar increase in $\mathrm{f0}$ was mainly linked to English. This suggests a larger degree of age-based uniformity of productions in the dominant language, as opposed to the HL, where there is greater heterogeneity, as also attested in the results for speech rate. The reasons for this heterogeneity could be tied to variables that were not explored in depth in the current study; for example, the Spanish-speaking social networks of each age group may manage sarcasm vs. sincerity strategies differently (see Alvord 2010 for a discussion of social networks' effect on bilingual intonation). Another explanation could come from source input varieties, which is a topic we will delve into when addressing the implications of our analysis of the Spanish productions of generations within the same family.

Regardless of these exceptions pointed out above, overall, it appears that the prosodic expressions of sarcasm and sincerity (and the contrast between them) of our HSS take a similar form in both of their languages, but that in Spanish, relative to English, the speech rate is shifted down and both $\mathrm{f0}$ measures are shifted up. This begs the question: what issues related to Spanish and English are causing these shifts in values?

Recall that, based on the BLP scores in Figure 1, we classified all our HSS as Englishdominant. This becomes key here because it will help explain our results. In terms of speech rate, Spanish speech is most likely slower due to the fluency of the participants in their two languages; that is, they generally speak faster in English, their dominant language, than in Spanish, their HL, a tendency that was borne out in the task they completed for this study (see Bosker et al. 2012 for details on speech rate's link to fluency). Second, in order to account for the generally elevated f0 mean of Spanish, relative to English, we resort to Gussenhoven's (2002) biological codes, which he proposed as a way of explaining the 
relationship between intonation and pragmatic meaning across languages. In particular, the Frequency Code, grounded in the anatomical differences between males and females that generate natural gender-based differences in the realization of $\mathrm{f} 0$, claims that relative increases in $\mathrm{fO}$ can be associated with stances such as politeness, submissiveness, and a lack of certainty or confidence. Since our HSS are English-dominant, we can infer that they are less certain or confident when speaking in their HL, Spanish, which could have the consequence of raising their $\mathrm{f} 0$ mean relative to that of English, while still maintaining the same $\mathrm{f} 0$ mean distinction to convey the attitudinal contrast in question across languages. Joining this point with the information presented above about learning to navigate sarcasm well into one's school years, at which point our HSS would have transitioned to Englishdominance, leads us to argue that our English f0 mean results represent a type of "baseline" manifestation of the attitudinal contrast in question, and our Spanish f0 mean data are filtered through the English system for each attitude and shifted upward, due to our HSS having less confidence in their HL. Finally, when placing our f0 range results beside previous studies involving this variable in Spanish and English, such as those of EstebasVilaplana (2014) and Harris et al. (2015), we note that while f0 excursions and range tend to be wider in English, our HSS data reveal the opposite pattern. ${ }^{4}$ Upon returning to the notion of English communication of sarcasm vs. sincerity as a baseline in our participants and adding the comments on sound system hybridity in heritage speakers by authors such as Kim (2019) and Kim and Repiso-Puigdelliura (2021), we suggest that our HSS start with a wider range in English than what we would expect in the Spanish of a Spanishdominant speaker, and then filter their Spanish productions through the English strategies, which cause them to draw upon the English feature of an increased f0 range, rather than suppressing it toward what we would expect in Spanish. By adopting English's range trend, the Spanish range data is thus boosted relative to those of English. In the Spanish iteration of our particular pragmatic condition, this is achieved at the expense of what we might expect, based on previous studies in which a weaker language has been linked to a narrowing of f0 range (see, e.g., Aoyama and Guion 2007; Busà and Urbani 2011; Peters 2019; Ullakonoja 2007). Another possibility would be to reference Gussenhoven's (2002) Effort Code, which states that increased emphasis and emotion are expressed by an expanded f0 range. This would likely require us to explore language affect in our HSS, which is a topic that is most suitable for future research. On the other hand, if we were to assume a language contact approach to heritage speakers (see Aalberse et al. 2019), we could draw parallels between the Spanish of our participants and contact varieties that show patterns of emphatic uses of f0, which are rendered somewhat unnatural in non-contact varieties (e.g., Korfhagen et al. 2021 and references therein). Overall, given that this HSS Spanish data are quite different from what one might expect in monolingual (or perhaps Spanish-dominant bilingual) speakers of Spanish, it would be interesting to use our data as stimuli in a perception test with monolingual Spanish (or Spanish-dominant) participants, to see if mismatches occur between perception vs. HSS intent.

An additional variable that merits discussion is bilingual type, which was involved in significant effects for both $\mathrm{f} 0$ mean and range. Interestingly, once again, salience is observed for the sincere attitude, thus supporting earlier comments on increased variation in our HSS being tied to literal speech rather than to expressions of verbal irony. Within sincerity, the two f0 variables demonstrated opposing trends; that is, for f0 mean, simultaneous bilinguals exhibited an increase, whereas for f0 range, sequential bilinguals showed expansion. This finding suggests that differing childhood experiences with respect to the dominant language and the HL may lend themselves to variation in the modulation of f0 to convey certain attitudes in adulthood. Given that, as we have mentioned, the contrast between sarcasm and sincerity typically does not develop in speech until well into one's school years, the driver behind the distinct f0 patterns we found could be a combination of pre-onset-ofschooling and post-onset-of-schooling linguistic experiences. This preliminary insight clearly deserves more future attention. 
The last significant variable that we have yet to mention in detail is dominance, which reveals that the middle group's (i.e., within the top and bottom quartiles of BLP scores) use of speech rate and $\mathrm{f} 0$ mean distinguishes itself from the other two groups. While we cannot offer a clear explanation for this interesting finding, one possibility worth exploring is that since they represent a mid-level of English dominance, they are the best example of a hybrid bilingual prosodic-pragmatic system (following, e.g., Kim 2019); for example, they may draw upon both of their prosodic systems in a unique way when compared to the other two groups, who may rely more heavily on one language or the other since they lie further toward either end of the dominance continuum. This is a tentative idea that should be investigated further down the line; nonetheless, we have shown that in similar studies, dividing up the category of "language dominance" could be a fruitful endeavor. Additionally, the high group's (in the top quartile of BLP scores) f0 range revealed significant expansion, particularly in the sincere condition. Given that this group could be characterized as the most English-dominant, such expansion makes sense since, as previously noted, wider f0 excursions and range are more commonly attributed to English. This implies that the high group showed more evidence of a commonly attested English pattern, and the fact that it occurred more in sincere samples provides further support for our claim that our HSS produce more variation when they really mean what they are saying vs. when they use speech non-literally and with the intent of being critical.

The analysis of a subset of participants belonging to the same family, but differing in language dominance, provides key commentary on the importance of source input varieties when looking into the linguistic outcomes of adult HSS, thus empirically supporting Pascual y Cabo and Rothman (2012) at an overarching level, and those such as Aziz et al. (Forthcoming) and Rao (2016) at the specific level that prosody plays in the expression of pragmatic meaning in heritage Spanish. The fact that there are no statistically significant differences in the outputs across this family, regardless of language dominance, is evidence that features of a minority language variety produced within a tight-knit community are transmitted cross-generationally. By carrying out this more specific analysis, we found out that, for example, within this family, speech rate is manipulated in an opposing fashion to the broader trends uncovered across the entire HSS data set. As such, based on our modest family-level data, we can suggest that the Spanish-dominant parents (and perhaps other Spanish-dominant members of their family residing in the same area) have had an influence on the way in which the HSS of this particular family express sarcasm vs. sincerity when speaking Spanish as an HL. Given that the pragmatic condition investigated here most likely is expressed among individuals with whom one is very comfortable and unguarded, it is logical that the strategies produced by individuals generally reflect one another. It is also worth noting that six of the seven English-dominant participants within this family fall in the older age group of the general analysis, which could partially account for the distinct trends found in that group vs. the younger group. Overall, since many HSS primarily speak their HL with family members of older generations, such as parents and grandparents, we would like to highlight that in the future, it is paramount to obtain data and make comparisons within families (as well as across other variables) when researching heritage speakers. While this could be logistically challenging, it is a worthwhile goal because it could enhance our high-level knowledge of the linguistic system of adult heritage speakers in a unique way.

\section{Conclusions}

This study aimed to identify how the attitudes of sarcasm and sincerity are expressed in both Spanish and English by HSS, based on interactions among the sociolinguistic variables of gender, bilingual type, place of birth, language dominance, and age and the suprasegmental variables of $\mathrm{f0}$ mean, $\mathrm{fO}$ range, and speech rate, and how this attitudinal contrast is expressed by members within the same family. Important takeaways show that patterns of prosodic manifestations of attitude for HSS are overall similar in both English and Spanish, despite differing values for speech rate, $\mathrm{f0}$ mean, and $\mathrm{f0}$ range, and that, as a 
whole, HSS data in this study are distinct from what we might expect from monolingual or Spanish-dominant bilinguals, therefore presenting a unique avenue for future research with respect to the perceptions of attitude by monolingual/Spanish-dominant bilinguals, as produced by HSS.

The results of the current study show great potential for expansion related to the sociolinguistic variables explored here. In particular, the effect of $\mathrm{f} 0$ range according to speaker gender when comparing HSS and adult-immigrant bilinguals could provide insight into how unique childhood and adolescent language profiles may impact prosodic manifestations of sarcasm and sincerity in adults. Although birthplace did not yield significant results in our study, given the f0 differences we observed in simultaneous vs. sequential bilinguals, future work should further explore the role that early exposure to the dominant language, or a lack thereof, could play in determining prosodic-pragmatic outcomes in adulthood. Furthermore, analyzing language dominance according to three subcategories shows that mid-level and high-level English-dominant HSS demonstrate unique tendencies. More work in this area could, for example, solidify a hybrid bilingual prosodic-pragmatic system for mid-level English-dominant HSS, instead of relying more on either one language or the other. While the familial data analyzed for this study include members from only one family, the lack of statistically different results among these family members suggests that minority language features are transmitted cross-generationally, regardless of language dominance. This conclusion places increased importance on collecting data and making comparisons within families with respect to heritage speakers, to explore a more comprehensive understanding of the linguistic system of adult HSS. Finally, an important direction for future research involves participants' social networks, a variable not explored in this study, which could shed increased light on various aspects of the findings elaborated here.

Overall, this study contributes to the new and growing body of research on the prosody-pragmatics interface of HSS by exploring various sociolinguistic factors that affect the expression of sarcasm and sincerity in Spanish and English, as well as the effect of source input variety within members of the same family, highlighting the role of unique language experiences and sociolinguistic variables in the expression of attitude among HSS.

Author Contributions: Conceptualization, R.R.; methodology, R.R.; formal analysis, R.R., B.B. and T.Y.; investigation, R.R.; resources, R.R.; writing-original draft preparation, R.R., B.B. and T.Y.; writing — review and editing, R.R. and B.B.; project administration, R.R.; funding acquisition, R.R. All authors have read and agreed to the published version of the manuscript.

Funding: This research was funded by The University of Wisconsin-Madison's Office of the Vice Chancellor for Research and Graduate Education, grant number MSN194282.

Institutional Review Board Statement: The study was conducted in accordance with the Declaration of Helsinki, and approved by the Institutional Review Board of The University of Wisconsin-Madison (protocol code 2013-0690, approved on 17 October 2015).

Informed Consent Statement: Informed consent was obtained from all subjects involved in the study.

Data Availability Statement: The data presented in this study are available upon request from the corresponding author. The data are not publicly available due to ethical considerations.

Acknowledgments: We are extremely grateful to Alexandra Galván for the time and energy she invested in the recruitment and recording of participants, and the organization of the entire data set. This study would not have been possible without her contributions. We would also like to thank Erwin Lares and Margaryta Bondarenko for their help with the acoustic analysis. Finally, we express our gratitude to three anonymous reviewers and the academic editors of this special issue, Christine Shea and Ji Young Kim, for providing constructive feedback on a previous version of this paper.

Conflicts of Interest: The authors declare no conflict of interest. 


\section{Appendix A}

\begin{tabular}{|c|c|c|c|c|c|c|}
\hline Participant ID & Age (Age Group) & Gender & Place of Birth & Bilingual Type & $\begin{array}{l}\text { BLP } \\
\text { Score }\end{array}$ & $\begin{array}{c}\text { English } \\
\text { Dominance }\end{array}$ \\
\hline ENG03 & $23(18-30)$ & $\begin{array}{l}\text { Female } \\
\text { (F) }\end{array}$ & US & Simultaneous (Sim) & 65.8 & Mid (M) \\
\hline ENG04 & $51(30+)$ & $\mathrm{F}$ & US & Sequential (Seq) & 52.2 & Low (L) \\
\hline ENG05 & $20(18-30)$ & F & US & Sim & 80.8 & $\mathrm{M}$ \\
\hline ENG08* & $50(30+)$ & $\begin{array}{l}\text { Male } \\
\text { (M) }\end{array}$ & Mexico & Seq & 118.9 & $\operatorname{High}(\mathrm{H})$ \\
\hline ENG12* & $40(30+)$ & M & US & Sim & 46 & $\mathrm{~L}$ \\
\hline ENG13 & $36(30+)$ & $\mathrm{F}$ & US & Sim & 116.3 & $\mathrm{H}$ \\
\hline ENG14 & $35(30+)$ & M & US & Sim & 42.4 & $\mathrm{~L}$ \\
\hline ENG15 & $20(18-30)$ & M & US & Sim & 94.1 & M \\
\hline ENG16 & $52(30+)$ & M & Mexico & Seq & 102.3 & M \\
\hline ENG17 & $43(30+)$ & M & US & Sim & 75.1 & M \\
\hline ENG19 & $23(18-30)$ & $\mathrm{F}$ & US & Sim & 58.2 & M \\
\hline ENG20 & $40(30+)$ & $\mathrm{F}$ & US & Seq & 64.2 & M \\
\hline ENG21* & $18(18-30)$ & $\mathrm{F}$ & US & Sim & 117.5 & $\mathrm{H}$ \\
\hline ENG22 * & $45(30+)$ & $\mathrm{M}$ & Mexico & Seq & 36 & $\mathrm{~L}$ \\
\hline ENG23 * & $44(30+)$ & $\mathrm{F}$ & Mexico & Sim & 129.1 & $\mathrm{H}$ \\
\hline ENG24 & $26(18-30)$ & $\mathrm{F}$ & US & Sim & 84.6 & $\mathrm{M}$ \\
\hline ENG25 & $19(18-30)$ & F & US & Seq & 37.5 & $\mathrm{~L}$ \\
\hline ENG26 * & $49(30+)$ & F & Mexico & Seq & 76.9 & M \\
\hline ENG27* & $46(30+)$ & F & Mexico & Seq & 115.4 & $\mathrm{H}$ \\
\hline
\end{tabular}

Relevant background information on the 19 English-dominant HSS participants. The seven participant IDs with an asterisk $\left(^{*}\right)$ next to them form part of the family-level analysis (along with the three participants in Appendix B).

\section{Appendix B}

\begin{tabular}{ccccc}
\hline Participant ID & Age & Gender & Place of Birth & BLP Score \\
\hline SPA06 & 81 & Female (F) & Mexico & -183.1 \\
SPA07 & 73 & F & Mexico & -69.6 \\
SPA10 & 48 & F & Mexico & -15.7 \\
\hline
\end{tabular}

Relevant background information on the three Spanish-dominant adult immigrant participants who formed part of the family-level analysis.

\section{Notes}

1 As pointed out by an anonymous reviewer, research on the prosody of sarcasm should be mindful of the various types of sarcasm when interpreting results. Given that the current study is, to our knowledge, the first of its kind, teasing apart the effects on prosody of subcategories of sarcasm in the speech of heritage speakers is a topic left for future work.

2 For work on perception-based investigations, see Bryant and Fox Bryant and Tree (2002, 2005); Rockwell (2000b, 2007); Voyer and Techentin (2010).

3 An anonymous reviewer notes that further exploration of the homeland varieties linked to heritage speakers would be a useful point to consider in related research. To date, the lack of studies on our dependent variables of interest as they pertain to varieties of Mexican Spanish leads us to leave the reviewer's observation as a consideration for future work.

4 While this is generally the case when comparing $\mathrm{f} 0$ in Spanish and English, an anonymous reviewer points out that f0 range can demonstrate variation across varieties of a given language (see Mennen et al. 2012, 2014 and references therein).

\section{References}

Aalberse, Suzanne, Ad Backus, and Pieter Muysken. 2019. Heritage Languages: A Language Contact Approach. Amsterdam: John Benjamins.

Ackerman, Brian. 1983. Form and function in children's understanding of ironic utterances. Journal of Experimental Child Psychology 35: 487-508. [CrossRef]

Adachi, Takanori. 1996. Sarcasm in Japanese. Studies in Language 20: 1-36. [CrossRef]

Alvord, Scott. 2010. Variation in Miami Cuban Spanish interrogative intonation. Hispania 93: 235-55.

Amengual, Mark. 2019. Type of early bilingualism and its effect on the acoustic realization of allophonic variants: Early sequential and simultaneous bilinguals. International Journal of Bilingualism 23: 954-70. [CrossRef]

Aoyama, Katsura, and Susan Guion. 2007. Prosody in second language acquisition: Acoustic analysis of duration and F0 range. In Language Experience in Second Language Speech Learning: In Honor of James Emil Flege. Edited by Ocke-Schwen Bohn and Murray Munro. Amsterdam: John Benjamins, pp. 281-97. 
Attardo, Salvatore, Jodi Eisterhold, Jennifer Hay, and Isabella Poggi. 2003. Multimodal markers of irony and sarcasm. HumorInternational Journal of Humor Research 16: 243-60. [CrossRef]

Aziz, Jacob, Natasha Swiderski, Vanina Machado, Celina Valdivia, Yasaman Rafat, Ryan Stevenson, and Rajiv Rao. Forthcoming. The intonation of absolute questions in Argentinian- and Venezuelan-Canadian heritage speakers of Spanish: Investigating parental and English influences. Spanish as a Heritage Language.

Bates, Douglas, Martin Mächler, Ben Bolker, and Steve Walker. 2015. Fitting linear mixed-effects models using lme4. Journal of Statistical Software 67: 1-48. [CrossRef]

Beckman, Mary, Manuel Díaz-Campos, Julia McGory, and Terrell Morgan. 2002. Intonation across Spanish, in the Tones and Break Indices framework. Probus 14: 9-36. [CrossRef]

Birdsong, David, Libby Gertken, and Mark Amengual. 2012. Bilingual Language Profile: An Easy-to-Use Instrument to Assess Bilingualism. Austin: COERLL, University of Texas at Austin. Available online: https://sites.la.utexas.edu/bilingual/ (accessed on 30 September 2015).

Blum-Kulka, Shoshana, and Hadass Sheffer. 1993. The metapragmatic discourse of American-Israeli families at dinner. In Interlanguage Pragmatics. Edited by Gabriele Kasper and Shoshana Blum-Kulka. New York: Oxford University Press, pp. 196-224.

Boersma, Paul, and David Weenink. 2020. Praat: Doing Phonetics by Computer [Computer program]. Version 6.1.16. Available online: http:/ / www.praat.org/ (accessed on 2 September 2020).

Bosker, Hans, Anne-France Pinget, Hugo Quené, Ted Sanders, and Nivja de Jong. 2012. What makes speech sound fluent? The contributions of pauses, speed and repairs. Language Testing 30: 159-75. [CrossRef]

Bousfield, Derek. 2008. Impoliteness in Interaction. Amsterdam and New York: John Benjamins.

Bryant, Gregory, and Jean Fox Tree. 2002. Recognizing verbal irony in spontaneous speech. Metaphor and Symbolic Activity 17: 99-117. [CrossRef]

Bryant, Gregory, and Jean Fox Tree. 2005. Is there an ironic tone of voice? Language and Speech 48: 257-77. [CrossRef] [PubMed]

Busà, Maria Grazia, and Martina Urbani. 2011. A cross linguistic analysis of pitch range in English L1 and L2. In Proceedings of the 17th International Congress of Phonetic Sciences. Edited by Wai Sum Lee and Eric Zee. Hong Kong: City University of Hong Kong, pp. 380-83.

Capelli, Carol, Noreen Nakagawa, and Cary Madden. 1990. How children understand sarcasm: The role of context and intonation. Child Development 61: 1824-41. [CrossRef]

Cheang, Henry, and Marc Pell. 2008. The sound of sarcasm. Speech Communication 50: 366-81. [CrossRef]

Cheang, Henry, and Marc Pell. 2009. Acoustic markers of sarcasm in Cantonese and English. Journal of the Acoustical Society of America 126: 1394-405. [CrossRef] [PubMed]

Cheang, Henry, and Marc Pell. 2013. Recognizing sarcasm without language: A cross-linguistic study of English and Cantonese. In Prosody and Humor. Edited by Salvatore Attardo, Manuela Maria Wagner and Eduardo Urios-Aparisi. Amsterdam and Philadelphia: John Benjamins, pp. 15-35.

Chen, Aoju, and Diantha De Jong. 2015. Prosodic expression of sarcasm in L2 English. In L2 Spoken Discourse: Pragmatic and Prosodic Aspects. Edited by Marina Chini. Milano: FrancoAngeli, pp. 27-37.

Colantoni, Laura, Alejandro Cuza, and Natalia Mazzaro. 2016. Task related effects in the prosody of Spanish heritage speakers. In Intonational Grammar in Ibero-Romance: Approaches Across Linguistic Subfields. Edited by Meghan Armstrong, Nicholas Henriksen and Maria Vanrell. Amsterdam: John Benjamins, pp. 3-24.

Cruttenden, Alan. 1984. Intonational misfits. In Intonation, Accent and Rhythm. Edited by Dafydd Gibbon and Helmut Richter. Berlin: De Gruyter, pp. 67-76.

Culpeper, Jonathan. 2005. Impoliteness and entertainment in the television quiz show: The Weakest Link. Journal of Politeness Research 1: 35-72. [CrossRef]

Cutler, Anne, Delphine Dahan, and Wilma van Donselaar. 1997. Prosody in the Comprehension of Spoken Language: A Literature Review. Language and Speech 40: 141-201. [CrossRef]

De-la-Mota, Carme, Pedro Martín Butragueño, and Pilar Prieto. 2010. Mexican Spanish intonation. In Transcription of Intonation of the Spanish Language. Edited by Pilar Prieto and Paolo Roseano. Munich: Lincom, pp. 319-50.

Dews, Shelly, Joan Kaplan, and Ellen Winner. 1995. Why not say it directly? The social functions of irony. Discourse Processes 19: 347-67. [CrossRef]

Dews, Shelly, Ellen Winner, Joan Kaplan, Elizabeth Rosenblatt, Malia Hunt, Karen Lim, Angela McGovern, Alison Qualter, and Bonnie Smarsh. 1996. Children's understanding of the meaning and functions of verbal irony. Child Development 67: 3071-85. [CrossRef]

Dupoux, Emmanuel, Christophe Pallier, Nuria Sebastian, and Jacques Mehler. 1997. A destressing "deafness" in French? Journal of Memory and Language 36: 406-21. [CrossRef]

Elias, Maria. 2013. 'Tengo bien harto esperando en la línea' (I am fed up waiting in line): Complaint Strategies by Second-Generation Mexican-American Bilinguals. Unpublished Master's thesis, Arizona State University, Tucson, AZ, USA.

Estebas-Vilaplana, Eva. 2014. The evaluation of intonation: Pitch range differences in English and in Spanish. In Evaluation in Context. Edited by Geoff Thompson and Laura Alba-Juez. Amsterdam: John Benjamins, pp. 179-94.

Face, Timothy, and Pilar Prieto. 2007. Rising accents in Castilian Spanish: A revision of Sp_ToBI. Journal of Portuguese Linguistics 6: 117-46. [CrossRef]

Fonagy, Ivan. 1971. Synthèse de l'ironie (Overview of irony). Phonetica 23: 42-51. [CrossRef] 
Froemming, Brenda, and Rajiv Rao. 2021. The tritonal pitch accent in the broad focus declaratives of the Spanish spoken in Cuenca, Ecuador: An acoustic and sociolinguistic analysis. Estudios de Fonética Experimental (Journal of Experimental Phonetics) 29: 119-40.

García, Maryellen, and Elizabeth Leone. 1984. The use of directives by two Hispanic children: An exploration of communicative competence. In National Center of Bilingual Research Report Series. Los Alamitos: National Center for Bilingual Research, p. 25.

Gelman, Andrew, and Jennifer Hill. 2006. Data Analysis Using Regression and Multilevel/Hierarchical Models. Cambridge: Cambridge University Press.

Gerrig, Richard, and Yegeniya Goldvarg. 2000. Additive effects in the perception of sarcasm: Situational disparity and echoic mention. Metaphor and Symbol 15: 197-208. [CrossRef]

Gibbs, Raymond. 2000. Irony in talk among friends. Metaphor and Symbol 15: 5-27. [CrossRef]

Glenwright, Melanie, and Penny Pexman. 2010. Development of children's ability to distinguish sarcasm and verbal irony. Journal of Child Language 37: 429-51. [CrossRef] [PubMed]

Glenwright, Melanie, Jayanthi Parackel, Kristene Cheug, and Elizabeth Nilsen. 2014. Intonation influences how children and adults interpret sarcasm. Journal of Child Language 41: 472-84. [CrossRef]

Gussenhoven, Carlos. 2002. Intonation and interpretation: Phonetics and phonology. In Proceedings of Speech Prosody 2002. Edited by Bernard Bel and Isabelle Marlien. Aix-en-Provence: Laboratoire Parole et Langage, pp. 47-57.

Gutiérrez-Rivas, Carolina. 2008. Actos de habla mixtos: Reflexiones sobre la pragmática del español en referencia a la teoría y métodos actuales de análisis. Núcleo 20: 149-71.

Gutiérrez-Rivas, Carolina. 2011. El efecto del género en el discurso bilingüe. Un estudio sobre peticiones. (The effect of gender in bilingual discourse. A study on requests). Estudios de Lingüística Aplicada 29: 37-59.

Haiman, John. 1998. Talk is Cheap: Sarcasm, Alienation, and the Evolution of Language. New York: Oxford University Press.

Hancock, Jeffrey, Philip Dunham, and Kelley Purdy. 2000. Children's comprehension of critical and complimentary forms of verbal irony. Journal of Cognition E Development 1: 227-48.

Harris, Melanie, and Penny Pexman. 2003. Children's perceptions of the social functions of verbal irony. Discourse Processes 36: 147-65. [CrossRef]

Harris, Michael, Viola Miglio, and Stefan Th. Gries. 2015. Mexican and Chicano prosody: Differences related to information structure. In Proceedings of the 6th Annual Pronunciation in Second Language Learning and Teaching Conference. Edited by John Levis, Rania Mohammed, Manman Qian and Ziwei Zhou. Ames: Iowa State University, pp. 40-50.

Haverkate, Henk. 1984. Speech Acts, Speakers, and Hearers. Amsterdam: John Benjamins.

Heredia, Roberto, and Anna Cieślicka. 2015. Bilingual Figurative Language Processing. Cambridge: Cambridge University Press.

Hualde, José Ignacio, and Pilar Prieto. 2016. Towards an International Prosodic Alphabet (IPrA). Laboratory Phonology 7: 1-25. [CrossRef]

Keenan, Thomas, and Kathleen Quigley. 1999. Do young children use echoic information in their comprehension of sarcastic speech? A test of echoic mention theory. British Journal of Developmental Psychology 17: 83-96. [CrossRef]

Kim, Jiyun. 2014. How Korean EFL learners understand sarcasm in L2 English. Journal of Pragmatics 60: 193-206. [CrossRef]

Kim, Ji Young. 2019. Heritage speakers' use of prosodic strategies in focus marking in Spanish. International Journal of Bilingualism 23: 986-1004. [CrossRef]

Kim, Ji Young, and Gemma Repiso-Puigdelliura. 2021. Keeping a Critical Eye on Majority Language Influence: The Case of Uptalk in Heritage Spanish. Languages 6: 13. [CrossRef]

Kissling, Elizabeth. 2018. An exploratory study of heritage Spanish rhotics: Addressing methodological challenges of heritage language phonetics research. Heritage Language Journal 15: 25-70. [CrossRef]

Korfhagen, David, Rajiv Rao, and Sandro Sessarego. 2021. Declarative intonation in four Afro-Hispanic varieties: Phonological analysis and implications. In Aspects of Latin American Spanish Dialectology. In Honor of Terrell A. Morgan. Edited by Manuel Díaz-Campos and Sandro Sessarego. Amsterdam: John Benjamins, pp. 155-79.

Ladd, D. Robert. 2008. Intonational Phonology, 2nd ed. Cambridge: Cambridge University Press.

Laval, Virginie, and Alain Bert-Erboul. 2005. French-speaking children's understanding of sarcasm: The role of intonation and context. Journal of Speech, Language, and Hearing Research 48: 610-20. [CrossRef]

Leech, Geoffrey. 1983. Principles of Pragmatics. New York: Longman.

Mandler, Jean. 1979. Categorical and schematic organization in memory. In Memory, Organization, and Structure. Edited by Richard Puff. New York: Academic Press, pp. 259-99.

Mennen, Ineke, Felix Schaeffler, and Gerard Docherty. 2012. Cross-language differences in fundamental frequency range: A comparison of English and German. Journal of the Acoustical Society of America 131: 2249-60. [CrossRef] [PubMed]

Mennen, Ineke, Felix Schaeffler, and Catherine Dickie. 2014. Second language acquisition of pitch range in German learners of English. Studies in Second Language Acquisition 36: 303-29. [CrossRef]

Montrul, Silvina Andrea. 2012. The grammatical competence of Spanish heritage speakers. In Spanish as a Heritage Language in the United States. Edited by Sara Beaudrie and Marta Fairclough. Washington, DC: Georgetown University Press, pp. 101-20.

Oprea, Silviu Vlad, and Walid Magdy. 2020. The effect of sociocultural variables on sarcasm communication online. Proceedings of the ACM on Human-Computer Interaction 4: 1-22. [CrossRef]

Pascual y Cabo, Diego, and Jason Rothman. 2012. The (il)logical problem of heritage speaker bilingualism and incomplete acquisition. Applied Linguistics 33: 1-7. 
Passoni, Elisa, Adib Mehrabi, Eroz Levon, and Esther de Leeuw. 2018. Bilingualism, pitch range and social factors: Preliminary results from sequential Japanese-English bilinguals. Proceedings of Speech Prosody 2018: 384-88.

Pavlenko, Aneta. 2006. Bilingual Minds. Bristol: Multilingual Matters. [CrossRef]

Peters, Jörg. 2019. Fluency and speaking fundamental frequency in bilingual speakers of high and low German. In Proceedings of the 19th International Congress of Phonetic Sciences, Melbourne, Australia 2019. Edited by Sasha Calhoun, Paola Escudero, Marija Tabain and Paul Warren. Canberra: Australasian Speech Science and Technology Association Inc., pp. 1655-59.

Peters, Sara, Kathryn Wilson, Timothy Boiteau, Carlos Gelormini-Lezama, and Amit Almor. 2016. Do you hear it now? A native advantage for sarcasm processing. Bilingualism: Language and Cognitition 19: 400-14. [CrossRef]

Pierrehumbert, Janet. 1980. The Phonology and Phonetics of English Intonation. Doctoral dissertation, MIT, Cambridge, MA, USA.

Pinto, Derrin. 2018. Heritage Spanish pragmatics. In The Routledge Handbook of Spanish as a Heritage Language. Edited by Kim Potowski. London and New York: Routledge, pp. 190-202.

Pinto, Derrin, and Richard Raschio. 2007. A comparative study of requests in heritage speaker Spanish, L1 Spanish, and L1 English. International Journal of Bilingualism 11: 135-55. [CrossRef]

Pinto, Derrin, and Richard Raschio. 2008. Oye, ¿qué onda con mi dinero? An analysis of heritage speaker complaints. Sociolingusitic Studies 2: 221-49. [CrossRef]

Potowski, Kim. 2007. Language and Identity in a Dual Immersion School. Clevedon: Multilingual Matters.

Rao, Rajiv. 2013. Prosodic consequences of sarcasm versus sincerity in Mexican Spanish. Concentric: Studies in Linguistics 39: 33-59.

Rao, Rajiv. 2016. On the nuclear intonational phonology of heritage speakers of Spanish. In Advances in Spanish as a Heritage Language. Edited by Diego Pascual y Cabo. Amsterdam and Philadelphia: John Benjamins, pp. 51-80.

Rao, Rajiv. 2019. The phonological system of adult heritage speakers of Spanish in the United States. In The Routledge Handbook of Spanish Phonology. Edited by Sonia Colina and Fernando Martínez-Gil. London and New York: Routledge, pp. 439-52.

Rao, Rajiv, and Mark Amengual. 2021. The phonetics and phonology of heritage Spanish. In Aproximaciones al estudio del español como lengua de herencia. Edited by Diego Pascual y Cabo and Julio Torres. London and New York: Routledge, pp. 11-23.

Robles-Puente, Sergio. 2014. Prosody in Contact: Spanish in Los Angeles. Doctoral dissertation, University of Southern California, Los Angeles, CA, USA.

Rockwell, Patricia. 2000a. Actors', partners', and observers' perceptions of sarcasm. Perceptual and Motor Skills 91: 665-8. [CrossRef]

Rockwell, Patricia. 2000b. Lower, slower, louder: Vocal cues of sarcasm. Journal of Psycholinguistic Research 29: 483-95. [CrossRef]

Rockwell, Patricia. 2005. Sarcasm on television talk shows: Determining speaker intent through verbal and nonverbal cues. In Psychology of Moods. Edited by Anita Clark. New York: Nova Science, pp. 109-40.

Rockwell, Patricia. 2007. Vocal features of conversational sarcasm: A comparison of methods. Journal of Psycholinguistic Research 36: 361-69. [CrossRef]

Shively, Rachel. 2021. Researching Spanish heritage language pragmatics in study abroad. In Heritage Speakers of Spanish and Study Abroad. Edited by Rebecca Pozzi, Tracy Quan and Chelsea Escalante. New York and London: Routledge, pp. 101-16.

Silva-Corvalán, Carmen. 1994. The gradual loss of mood distinctions in Los Angeles Spanish. Language Variation and Change 6: 255-72. [CrossRef]

Silva-Corvalán, Carmen. 2001. Sociolingüística y pragmática del español. (Sociolinguistics and pragmatics of Spanish). Washington, DC: Georgetown University Press.

Skoog Waller, Sara, and Mårten Eriksson. 2016. Vocal age disguise: The role of fundamental frequency and speech rate and its perceived effects. Frontiers in Psychology 7: 1-10. [CrossRef] [PubMed]

Ullakonoja, Riikka. 2007. Comparison of pitch range in Finnish (L1) and Russian (L2). In Proceedings of the 16th International Congress of Phonetic Sciences. Edited by Jürgen Trouvain and William Barry. Saarbrücken: Saarbrücken University, pp. 1701-4.

Ushakova, Tatiana. 1994. Inner speech and second language acquisition: An experimental-theoretical approach. In Vygotskian Approaches to Second Language Research. Edited by James Lantolf and Gabriela Appel. Norwood: Ablex, pp. 135-56.

Voyer, Daniel, and Cheryl Techentin. 2010. Subjective auditory features of sarcasm. Metaphor and Symbol 25: 227-42. [CrossRef]

Walter, Joel. 1981. Variation in the requesting behavior of children. International Journal of the Sociology of Language 27: 77-92. [CrossRef]

Wichmann, Anne. 2000. The Attitudinal Effects of Prosody, and How They Relate to Emotion. Available online: https://www.iscaspeech.org/archive_open/archive_papers/speech_emotion/spem_143.pdf (accessed on 4 June 2021).

Winner, Ellen. 1988. The Point of Words. Cambridge: Harvard University Press.

Winner, Ellen, and Sue Leekam. 1991. Distinguishing irony from deception: Understanding the speaker's second-order intention. British Journal of Developmental Psychology 9: 257-70. [CrossRef]

Xiao-Desai, Yang. 2019. Heritage Learner Pragmatics. In Handbook of SLA and Pragmatics. Edited by Naoko Taguchi. New York: Routledge, pp. 462-78.

Zárate-Sández, Germán. 2015. Perception and Production of Intonation among English-Spanish Bilingual Speakers at Different Proficiency Levels. Doctoral dissertation, Georgetown University, Washington, DC, USA. 